NASA Technical Paper 1712

\title{
Effects of Conversation Interference on Annoyance Due to Aircraft Noise
}

Kelli F. Key and Clemans A. Powell

AUGUST 1980 
NASA Technical Paper 1712

\section{Effects of Conversation Interference on Annoyance Due to Aircraft Noise}

Kelli F. Key and Clemans A. Powell

Langley Research Center

Hampton, Virginia

\section{N/Sก}

National Aeronautics

and Space Administration

Scientific and Technical

Information Branch

1980 


\section{SUMMARY}

The annoyance and interference effects of aircraft flyover noise on faceto-face conversation were investigated. Twenty 5-minute sessions of three flyovers each session were presented to each of 20 pairs of female subjects in a simulated living room. Flyovers varied in noise level (55 to $79 \mathrm{~dB}$, A-weighted) and spectrum (low- or high-frequency components). Subjects engaged in conversation for 10 sessions and in reverie for the other 10 sessions, and completed subjective ratings following every session. The ratings concerned the annoyance of the noise, the difficulty of conversing in the noise, and the acceptability of the noise for conversation. Conversation interference was defined as an increase in vocal effort or a cessation of talking during a flyover.

Annoyance was affected by noise level but was not significantly different for the activities of reverie and conversation. A noise level of $77 \mathrm{~dB}$ (A-weighted) was found to be unacceptable for conversation by 50 percent of the subjects. Although conversation interference increased with noise level, conversation interference measures did not improve prediction of individual annoyance judgments.

\section{INTRODUCTION}

Cammunity annoyance to aircraft noise has been implied, through reported surveys, to be greatly influenced by interference with communication activities. Examples of such activities include television viewing, telephone conversation, and face-to-face conversation. Although suggesting directions for research, the surveys themselves have not provided detailed information about the influence of communication interference on annoyance.

The second Heathrow survey of the London community (ref. 1) is a case in point. A substantial correlation of 0.56 was found between aircraft flyover noise annoyance and respondent's reports of conversation interference as well as television-viewing and radio-listening interference. However, the actual amount and type of communication interference was not measured; consequently, little specific information was obtained about these activities and their relationship to annoyance.

Reference 2 reported a study that dealt directly with communication interference. In that laboratory study, communication interference was investigated by presenting a listening task to subjects while exposed to helicopter interior noise of various spectra. As expected, annoyance increased with noise level. In addition, annoyance was greater for listening conditions than for reverie conditions, which involved sitting quietly. Although differences in annoyance ratings were found for the various spectral conditions employed in the study, confounding of noise levels and spectra precluded attributing the annoyance differences either to spectrum or to level. 
Identification of the most appropriate noise descriptor or metric for relating annoyance to aircraft noise is also an important issue. Although this has been investigated in previous studies, no consensus has been established. For example, in reference 2 it was reported that $L_{A}$ (A-weighted sound level) had a higher correlation than SIL (speech interference level) and OASPI (overall sound pressure level), to the annoyance responses during the reverie conditions, whereas $I_{A}$ and SIL had statistically equal correlations to the annoyance during the listening conditions. The most appropriate descriptor of subjects' responses to communication interference was also addressed in a laboratory study reported in reference 3. In that study, communication interference was investigated in the form of face-to-face conversation during continuous general aviation noise of various spectra. However, because only conversation conditions were tested, no comparisons with nonconversation or reverie conditions could be made. It was found that $\mathrm{L}_{A}$ and SIL were equally highly correlated descriptors of subjects' responses of difficulty of conversation and acceptability of the noise for conversation. Similar to findings of reference 2, no differences in the above responses due to spectra were found.

The present laboratory research was conducted to investigate systematically the annoyance effects of interference attributed to aircraft-noise exposure during casual face-to-face conversation. Specific objectives of the study were (1) the determination of the degree of conversation interference during an aircraft flyover noise; (2) the determination of the relationship between these conversation interference measures and the subjects' corresponding annoyance judgments; (3) the comparison of the noise annoyance judgments made while engaged in conversation with those made in reverie; and (4) the determination of the noise metric that is most highly correlated with the aforementioned annoyance. The details of the experimental design and results of the experiment relevant to these objectives are reported herein.

\section{SYMBOLS AND ABBREVIATIONS}

More details of the indices and scales for acoustical measurements can be found in a number of general noise references including reference 4.

EPNL effective perceived noise level, $d B$

F ratio of variances

$k$ number of levels of a variable

$\mathrm{L}_{\mathrm{A}} \quad \mathrm{A}$-weighted sound pressure level, $\mathrm{dB}$

n number of observations in a group

OASPL overall sound pressure level, dB

PNLT perceived noise level, tone-corrected, dB

Q weighted ratio of sums of squares 
Pearson product-moment correlation coefficient

$\mathbf{R}$

SIL

SPL

SS

$t$-value

\author{
Pearson product-moment multiple correlation coefficient
}

speech interference level based on 500-, 1000-, 2000-, and 4000-Hz octave bands, $\mathrm{dB}$

sound pressure level, dB

sum of squares

test of the significance of the difference between two correlation coefficients for nonindependent samples

EXPERIMENTAL METHOD

Test Facility

The interior effects room of the Langley Aircraft Noise Reduction Laboratory (fig. 1) was used in the present experiment. This room was designed to resemble a typical living room and to allow controlled acoustical environments to be presented to subjects. The construction of the test room is typical of modern single-family dwellings.

The loudspeaker systems used to produce the airplane noise stimuli were located outside the test room to provide a realistic simulation of residential airplane noise. Reference 5 presents an additional description of the facility and the results of acoustic measurements which indicated that airplane noises presented to test subjects in this facility are representative of those measured inside typical dwellings.

\section{Noise Stimuli}

The noise stimuli presented to subjects in the interior effects room were tape recordings made approximately $1.6 \mathrm{~km}$ from touchdown of Boeing 707 and Concorde landings. These airplanes were chosen because of their contrasting spectra, which may possibly produce different annoyance responses. The noiselevel time histories and one-third octave spectra of both aircraft recordings as measured in the subject seats (fig. 1) are reproduced in figures 2 to 5 . The spectrum in each figure is the energy-averaged SPL over all 0.5-second intervals of the flyover for each one-third octave band. Comparisons of these figures reveal that the noise characteristics of the 707 contain more intense tonal components above $1000 \mathrm{~Hz}$ than the Concorde noise, which predominantly consists of frequencies below $500 \mathrm{~Hz}$. The recordings were adjusted to be of nearly the same duration, 40 seconds, by rolling off at the rate of 10 dB per second, the beginning and end of the 707 recording to resemble that of the Concorde (figs. 2 to 5). For brevity, the 707 spectrum and the concorde spectrum will be referred to as the high- and low-frequency spectrum, respectively. 
Five levels, in 6-dB increments, of each recording were used. These levels were $79,73,67,61$, and $55 \mathrm{~dB}$, peak in terms of $\mathrm{L}_{\mathrm{A}}$ when averaged across the two seats and the two spectra. These levels are listed by seat and spectrum in table I for some widely used noise metrics. The differences in noise level between the left and right seat were statistically controlled as described in a subsequent section.

A computer-controlled tape recorder system was used to play back the proper flyover stimulus at the correct level and number of times during each session as determined by the preprogrammed experimental design described in the next section.

Design

A $2 \times 2 \times 5$ factorial repeated-measures design was selected for the study. There were two activities (conversation and reverie), two spectra, and five noise levels. Conversation was casual face-to-face conversation, and reverie was any quiet seated activity, such as reading. The latter two factors, spectrum and noise level, were discussed in the previous section. The orders of the level-spectrum conditions, counterbalanced in a Latin square, are presented by activity in table II. Listed at the left of each row are the number of the subject pair who received that particular activity for the first 10 sessions and the number of the subject pair who received it for the last 10 sessions. In other words, one-half of the subject pairs received 10 conversation sessions first, and one-half received 10 reverie sessions first. In total, 20 different 5-minute sessions were given to each pair of subjects. Each session consisted of three flyovers of the same spectrum and level.

\section{Dependent Measures}

Dependent measures were subjects' questionnaire responses and experimenter's ratings of conversation interference. The questionnaire responses consisted of ratings on scales of 0 to 10 of annoyance due to the noise and of difficulty of conversation in the noise, as well as a yes/no response for the acceptability of the noise for conversation. The questions are reproduced in the appendix.

Conversation interference was assessed by the experimenter from the recordings of the subjects' conversations. For each session, a count was made of the number of flyovers during which each subject increased her vocal effort (raised her voice). and/or stopped talking. The measures were dichotomous; that is, a subject did or did not increase her vocal effort and/or stop talking during a period of approximately 10 seconds about the maximum noise level of the flyover. Because there were three flyovers in each session, a subject's conversation interference count per session for each measure was either 3, 2, 1, or 0 . These counts were subsequently converted to percentage scores based on the number of subjects talking. More precisely, for a subject to have been rated as increasing her vocal effort or stopped talking, she had to have been talking immediately before the period of the maximum flyover noise level. Therefore, conversation interference scores were divided by the number of subjects talking 
rather than the total number of subjects, because some subjects were not talking prior to the maximum flyover noise level.

\section{Subjects}

The subjects were $\mathbf{4 0}$ paid female volunteers screened for normal hearing. They were obtained from the local community. The subjects were tested in pairs and in most cases, knew each other prior to the experiment. Ages ranged between 20 and 70 years, with a mean age of 38.5 years and a median age of 35 years.

\section{Procedure}

Upon arrival at the laboratory, the subject pair was seated approximately $2.7 \mathrm{~m}$ apart in the interior effects room and was given a set of instructions and questionnaires. A copy of the instructions is provided in the appendix. The subjects read the instructions and completed a consent form required of all participants in subjective experiments in this laboratory. The test conductor reviewed the instructions and questionnaires and answered any questions that the subjects had.

For the 10 conversation sessions, the subjects were instructed to converse as they would at home. For these sessions, lightweight lapel microphones were worn by the subjects so that their conversations could be tape-recorded for later analyses of conversation interference. For the 10 reverie sessions, the subjects were instructed not to talk, but to read or to do some other quiet activity, such as needlework. For all sessions, subjects were instructed to respond to the questionnaire after the end of each session. The intersession interval was 1 minute. The subjects had a 15-minute break at the end of the first 10 sessions.

\section{RESULTS AND DISCUSSION \\ Subjective Responses}

Annoyance.- A summary of the analysis of variance of the responses to the annoyance question is given in table III. Only noise level was found to be significant ( $p \leqq 0.01)$, and as indicated by the mean annoyance ratings in figure 6 , annoyance increased with noise level. Also indicated in figure 6 is a consistent trend for a slight activity difference, which is not statistically significant but does indicate that annoyance while engaged in conversation tended to be higher than annoyance while engaged in reverie. This trend agrees with the results of reference 2. Further analysis of the activity trend found in the present study revealed that annoyance was affected only by the noise level and not by the activity, beyond that which is related to noise level. This analysis is discussed in more detail in a later section.

The relationships between annoyance and noise level in terms of $I_{A}$ and PNLT are illustrated in figures $7(a)$ and $7(b)$ for the low- and high-frequency 
spectra. As in the case of activity, these spectrum trends are not statistically significant. In these figures, the noise levels have been averaged across the two subject seats for each aircraft type. However, there were also no significant annoyance differences between spectra or between seats when the noise levels were not averaged across the seats (figs. $8(a)$ and $8(b)$ ). Thus, even though samples of extreme spectra were presented to the subjects, no differences attributable to spectrum were found in their annoyance judgments.

Annoyance predictability.- Linear regressions of individual annoyance judgments on each of several noise metrics (PNLT, $L_{A}, S I L$, and EPNL) were computed using the noise levels at each seat. Linear analyses seem justified because there is not a great deviation from linearity, with the exception of the lowest noise level. The correlations between annoyance and each noise metric are listed in the right-hand column of table IV. In addition, the noise metric intercorrelations and t-test values are presented in the same table, upper right triangle and lower left triangle, respectively. The t-tests (ref. 6) were designed to test the significance of the difference between two correlation coefficients for nonindependent samples. There was no significant difference between the correlation coefficients of PNLT and $L_{A}$, and both were more highly correlated to annoyance than SIL. PNLT was more highly correlated to annoyance than EPNL. There was no significant difference between the correlation coefficients of EPNL and $L_{A}$ or SIL.

Results of the study in reference 2 were mixed also. In that study, it was indicated that $S I I$ and $\mathrm{L}_{\mathrm{A}}$ were equally highly correlated descriptors for annoyance responses during a listening task, but that $\mathrm{L}_{\mathrm{A}}$ was the most highly correlated descriptor for annoyance during reverie. Reference 3 also found that $L_{A}$ and SIL were equally highly correlated descriptors of noise acceptability during conversation. Neither reference 2 nor reference 3 reported the data in terms of PNLT.

When the correlations between annoyance and each noise metric are squared, the result $r^{2}$ represents the percent of variance in the annoyance response accounted for by the noise metric. PNLT accounted for the most variance, 29 percent, whereas EPNL accounted for the least, 27 percent. Although the 2 percent difference between these two noise metrics is statistically significant, this difference is probably due to the specific noises used. It is conceivable that if another set of noises were chosen, this difference would be changed or even eliminated. Therefore, in a practical sense, this small difference between metrics may not be very important.

Difficulty of conversation.- The second question on the questionnaire asked the subjects to rate the difficulty of conversing in the noise. The results of these ratings are presented in table $V$ as an analysis of variance summary. No significant difference was found for spectrum. Two factors, activity and noise level, were found to be significant. The relationships of these factors to difficulty of conversation are illustrated in figure 9. As can be seen in the figure, difficulty increases with noise level and is greater when the subjects were engaged in conversation than what they predicted while in reverie. The relationship in figure 9 closely resembles the relationship between annoyance and noise level shown in figure 6 . This similarity may imply that difficulty of conversation was a factor used by the subjects to evaluate annoyance. The activity dif- 
ference in figure 9 can be understood to mean that subjects underestimate their judgments of conversation difficulty in the noise when not actually engaged in conversation.

Acceptability of noise for conversation.- The underestimation of judgments found for difficulty of conversation was not manifested in the ratings for acceptability of noise for conversation. The decreased sensitivity of the dichotomous scale compared with the 11-point scale is at least partially responsible for the lack of underestimation. No significant difference for activity or spectrum was found in the analysis of variance summary presented in table VI. Noise level was the only significant factor.

The $Q$ values listed in table VI were computed, according to the method of reference 7, to test the sums of squares of the dichotomous data, the yes/no responses for acceptability. The dichotomous responses allowed the mean ratings to be viewed in terms of unacceptability of the noise for conversation by percent of subjects, as illustrated in figure 10. Unacceptability of noise for conversation increased with noise level. By interpolation, it can be seen that 50 percent of the subjects rated an $\mathrm{L}_{\mathrm{A}}$ value of $77 \mathrm{~dB}$ as unacceptable for conversation. This is compared with an $L_{A}$ value of $83 \mathrm{~dB}$ found by reference 3 for continuous interior aircraft noise.

\section{Conversation Interference}

It was necessary to determine whether the subjects were talking during the flyovers as instructed, before conversation interference effects could be examined. There was a total of 1200 flyovers during which subjects could have talked ( 3 flyovers/session $\times 10$ sessions $\times 40$ subjects). It was found that subjects talked during 770 flyovers, which is 64.17 percent of the total number of flyovers. (Sometimes both subjects talked during a flyover.)

Using analysis of variance, no differences were found between conditions. That is, there were absences of effects for spectrum and level whether or not a subject was talking when the flyover noise started. Therefore, it appears that the subjects followed instructions and talked as requested.

Vocal effort.- One measure of conversation interference was increased vocal effort. The experimenter subjectively assessed whether or not a subject increased her vocal effort (raised her voice) during the flyover relative to her voice level immediately prior to the 10-second period of maximum noise level. For each conversation session there were three flyovers, so that a subject could have been scored as raising her voice 3, 2, 1, or 0 times. The analysis of variance summary for these increased vocal effort data is presented in table VII. Using the Q-statistic to test the categorical data, only noise level was ascertained to be statistically significant.

Of the 770 subjects talking (as explained previously), 277 subjects increased their vocal effort. When this total of 277 was distributed by noise level, it was found that the number of subjects who raised their voices increased with noise level. This relationship is illustrated in figure 11 in terms of the percentage of subjects who increased their vocal effort based on 
the total number of subjects talking for each noise level. The data indicate that 71 percent of the subjects (or 117 out of 164 subjects talking) increased their vocal effort at the highest level $\left(L_{A}=79 \mathrm{~dB}\right)$. By interpolation, 50 percent raised their voices at $\mathrm{L}_{\mathrm{A}}$ equal to approximately $71 \mathrm{~dB}$.

Conversation interruption.- Table VIII presents the summary of the analysis of variance on the number of times subjects stopped talking during the flyover peaks. Again, as for vocal effort, categorical data were subjectively recorded by the experimenter as to whether the subjects did or did not stop talking during each flyover peak. The $Q$-tests again proved significant only for noise level.

of the 770 subjects who were talking during the flyovers, 86 subjects stopped talking. From figure 12, it can be seen that subjects stopped talking more often as noise level increased. At the highest noise level, 33 percent of the subjects (or 54 out of 164 subjects talking) stopped talking.

\section{Relationship Between Annoyance Response and Conversation Interference}

As previously discussed, results of analysis of variance indicated that noise level was a significant factor for annoyance, while activity and spectrum were insignificant. Of more interest in the present study is the relationship between the annoyance ratings and the conversation interference behaviors. In order to examine this relationship, it was necessary to statistically control for the effect of noise level on the annoyance ratings. Multiple regression covariate analysis provided this capability. Noise level was treated as a covariate for both conversation interference measures. Multiple regressions were run using the noise levels for each seat measured in PNLT, $L_{A}, S I L$, and EPNL. As discussed earlier, PNLT is a slightly more highly correlated descriptor than the other metrics examined. Therefore, only the regression results using PNLT are presented.

Vocal effort.- Noise level has been found to be significant through analysis of variance for all measures previously discussed. This finding was repeated in the multiple regression analysis of annoyance on vocal effort. The results of the multiple regression of annoyance on increased vocal effort covaried by PNLT for 400 observations are presented in table IX. As indicated in the table, only noise level was significant, accounting for 29 percent of the variance. The variables entered into the regression were noise level; increased vocal effort one, two, or three times per session; and the interactions of each of these with noise level. With the effect of noise level (PNLT) controlled in this manner, the analysis in table IX shows that the remaining variables are not statistically significant. As a group, they explain less than 1 percent additional variance in annoyance.

When noise level was not directly taken into account (not entered into the regression equation), increased vocal effort alone was found to account for only 12 percent of the variance in annoyance responses $(R=0.34)$. (The variables entered into the equation were increased vocal effort one, two, or three times per session.) However, when noise level was a covariate for increased vocal effort, no significant amounts of variance were accounted for by increased 
vocal effort. Therefore, inferring from the covariate analysis results, any significant amount of the 12 percent of variance accounted for by vocal effort is attributable to the noise level effect inherent in increased vocal effort.

The interpretation of this finding is that even though subjects increased their vocal effort during the flyovers, this behavior did not of itself independently influence the subjects' annoyance of those flyovers. That is to say, the behavior of increasing vocal effort occurred simultaneously with increased noise level, the latter of which was found to directly influence annoyance. Increasing vocal effort has an effect only in its relationship to noise level. It seems that there is nothing inherent in the behavior of raising one's voice that increases prediction ability of that individual's annoyance judgments beyond use of noise level.

Conversation interruption. - The analogous multiple regression analysis based on the number of times subjects stopped talking is given in table $x$ for 400 observations. Noise level (PNLT) was again the only significant factor. The difference between $\mathrm{R}^{2}$ for all the variables (PNLT; stopped talking one, two, or three times; and the interactions between these and PNLT) and $\mathrm{R}^{2}$ for PNLT alone is not statistically significant and explains less than 1 percent additional variance in annoyance ratings.

The amount of variance in the annoyance responses accounted for by conversation interruption alone was 6 percent $(R=0.25)$. As discussed above, any significant amount of the 6 percent accounted variance is attributable to the noise level effect associated with conversation interruption, as inferred from the regression analysis using noise level as a covariate. Apparently, conversation interference, as measured in this experiment, is so heavily dependent on noise level that no other aspect of the interference behavior has a significant effect.

Discussion.- The analysis of variance of annoyance ratings, examined previously, showed that annoyance did not differ by activity. This result is supported by the above multiple regression results; that is, neither conversation interruption nor increased vocal effort accounted for any significant anount of variance in the annoyance ratings in excess of that accounted for by noise level. In other words, conversation activity interference beyond the relationship to noise level had no effect on annoyance. Therefore, the regression results are in concurrence with the analysis of variance, and both indicate that noise level, but not activity apart from noise level, significantly affected annoyance.

The Heathrow survey (ref. 1) found that conmunication interference is an important factor of community annoyance to aircraft flyovers but did not attempt to separate communication interference effects from noise level. It also did not attempt to demonstrate that annoyance was greater with conversation interference than without it. As was seen in the present study, even though subjects rated conversing in high levels of noise difficult, the act of conversing did not influence their annoyance ratings of those levels, beyond that which was related to level. Therefore, contrary to inferences from community survey results and other studies, engaging in conversation made no significant difference in annoyance ratings or in acceptability of the aircraft flyover noise for 
conversation. Subjects possibly compensated for any conversation interference by increasing their vocal effort and/or stopping their conversation momentarily. However, these compensating behaviors were not reflected in the subjects' annoyance or acceptability ratings, and their inclusion in a regression equation did not increase the ability to predict these ratings.

The tasks employed in this experiment, casual face-to-face communication and reverie, were chosen as being representative of activities in which people engage frequently. No measure was made of the importance of these particular activities, and the results are not meant to be generalized to all communication activities. It is recognized that informational content, both sent and received, could be an important variable in some situations. A classroom situation would be an example of when it would be important to measure the amount and type of information transmitted and received. Interference in more complicated communication situations, such as the classroom, is an area of future research in the effects of aircraft noise annoyance.

\section{CONCLUSIONS}

This experiment was conducted to assess the annoyance and interference effects of aircraft flyovers on conversation. In the experiment, sessions of flyovers varying in noise level and spectrum were presented to pairs of subjects while engaged in conversation and in reverie. Listed below are conclusions from this experiment.

1. Annoyance due to aircraft noise and unacceptability of that noise for conversation increased with noise level. However, the above responses were not significantly different for the two activities of reverie and conversation.

2. Conversation interference in the form of increased vocal effort and of conversation interruption was also found to increase with noise level. However, conversation interference measures did not improve prediction of individual annoyance judgments when entered into the regression equation covaried by noise level.

3. Tone-corrected perceived noise level and A-weighted sound pressure level were found to be more highly correlated with annoyance than were effective perceived noise level and speech interference level. However, the differences between the correlation coefficients were small.

4. An A-weighted sound pressure level of $77 \mathrm{~dB}$ was found to be unacceptable for conversation by 50 percent of the subjects.

5. No differences due to spectra in annoyance, difficulty or acceptability of the noise for conversation, or conversation interference were found.

Langley Research Center

National Aeronautics and Space Administration

Hampton, VA 23665

July 22, 1980 


\section{APPENDIX}

\section{INSTRUCTIONS AND QUESTIONNAIRES}

\section{Instructions}

The experiment in which you are participating in today is to help us understand the reactions of people to various aircraft noise environments. There will be twenty sessions of aircraft noise, each lasting about five minutes. There will be a break after half of the sessions.

For half of the sessions, we would like you to talk to each other as much as possible. You may also do any craft work that you may have brought with you, however, please keep conversing whether or not you work.

A list of conversation topics will be shown to you to help you think of something to talk about should you need some suggestions. The only restricted topic is that of the present experiment. Other than that, you may talk about anything you wish. The subject matter is of no interest to us.

Please do not talk to each other between the sessions while responding to the questions on the scoring sheet. However, please talk as much as possible during the sessions.

During the other half of the sessions, we request that you do not talk nor express any emotion which might influence the response of the other person in the room. During each of the sessions, we would like you to relax and read or quietly do any craft work you may have brought with you.

You will be instructed beforehand as to which half of the sessions you are to talk and which half you are to remain quiet.

You will hear two short "beeps" at the beginning of a session, whereas the end of a session will be signalled by a single long beep.

At the end of every session, we would like you to make a few different judgments on the noise you just heard.

The session number will be indicated on a counter in the room. Please be sure that the scoring sheet, which you will be given, has this same session number.

The scoring sheet for each session will have two scales numbered "0 To $10 . "$ For one scale, the end points are labeled "NOT ANNOYING AT ALL" and "EXTREMELY ANNOYING." For the other scale, the end points are labeled "NOT DIFFICULT AT ALL" and "EXTREMELY DIFFICULT." An example of these scoring sheets is on the final page of this instruction set. Your judgment in all cases should be indicated by circling one of the numbers on the scale. For example, if you judge the noise to be very annoying then you should circle a number closer to the "EXTREMELY ANNOYING" end of the scale. Similarly if you judge the noise to be only slightly annoying you should circle a number closer to the "NOT ANNOYING 


\section{APPENDIX}

AT ALL" end of the scale. The same principle applies to the second question concerning the difficulty of conversing.

For the third question, you just put a check in the box beside the answer with which you most closely agree.

There are no correct answers; we just want a measure of your own personal reaction to the noise in each session. For this reason, we request that you do not talk about the tests, especially while responding to questions on the scoring sheet.

Thank you for participating in this investigation. 
APPENDIX

Questionnaire for Conversation Sessions

SCORING SHEET 1

Subject No.

Group

Seat

Session

Code

Date

1. How annoying was the noise in the session? (circle a number)

NOT ANNOYING AT ALL

$\begin{array}{llllllllllll}0 & 1 & 2 & 3 & 4 & 5 & 6 & 7 & 8 & 9 & 10 & \text { EXTREMELY ANNOYING }\end{array}$

2. How difficult was it to converse during the noise?

$\begin{array}{llllllllllllll}\begin{array}{c}\text { NOT DIFFICULT } \\ \text { AT ALL }\end{array} & 0 & 1 & 2 & 3 & 4 & 5 & 6 & 7 & 8 & 9 & 10 & \text { EXTREMELY DIFFICULT }\end{array}$

3. For conversing, the noise was - - (check one).

$\square$ ACCEP TABLE $\square$ NOT ACCEPTABLE 
APPENDIX

Questionnaire for Reverie Sessions

SCORING SHEET 2

Subject No.

Group

Seat

Session

Code

Date

1. How annoying was the noise in the session? (circle a number)

NOT ANNOYING

AT ALL

$$
\begin{array}{llllllllllll}
0 & 1 & 2 & 3 & 4 & 5 & 6 & 7 & 8 & 9 & 10 & \text { EXTREMELY ANNOY ING }
\end{array}
$$

2. How difficult would it have been to converse during the noise?

$\begin{array}{llllllllllllll}\text { NOT DIFFICULT } & 0 & 1 & 2 & 3 & 4 & 5 & 6 & 7 & 8 & 9 & 10 & \text { EXTREMELY DIFFICULT }\end{array}$

3. For conversing, the noise would have been - - (check one).

$\square$ АССЕРтAвLE

$\square$ NOT ACCEPTABLE 


\section{REFERENCES}

1. MIL Research, Ltd.: Second Survey of Aircraft Noise Annoyance Around London (Heathrow) Airport. Soc. Surv. Div., Off. Popul. Censuses \& Surv. (British), 1971.

2. Clevenson, Sherman A.; and Leatherwood, Jack D.: Effect of Noise Spectra and a Listening Task Upon Passenger Annoyance in a Helicopter Interior Noise Environment. NASA TP-1590, 1979.

3. Rupf, John A.: Noise Effects on Passenger Communication in Light Aircraft. [Preprint] 770446, Soc. Automot. Eng., Mar.-Apr. 1977.

4. Pearsons, Karl S.; and Bennett, Ricarda L.: Handbook of Noise Ratings. NASA CR-2376, 1974 .

5. Powell, Clemans A.: Effects of Road-Traffic Background Noise on Judgments of Individual Airplane Noises. NASA TP-1433, 1979.

6. Ferguson, George A.: Statistical Analysis in Psychology \& Education. Fourth ed. MoGraw-Hill Book Co., Inc., c. 1975 .

7. Winer, B. J.: Statistical Principles in Experimental Design. Second ed. MCGraw-Hill Book Co., Inc., C.1971. 
TABLE I.- MEASURED NOISE LEVELS

\begin{tabular}{|c|c|c|c|c|}
\hline \multirow{3}{*}{ Metric } & \multicolumn{4}{|c|}{ Measured noise level, $\mathrm{dB}$, at - } \\
\hline & \multicolumn{2}{|c|}{ Left seat } & \multicolumn{2}{|c|}{ Right seat } \\
\hline & Concorde & 707 & Concorde & 707 \\
\hline$L_{A}$ & $\begin{array}{l}53.0 \\
59.0 \\
65.0 \\
71.0 \\
77.0\end{array}$ & $\begin{array}{l}55.0 \\
67.0 \\
67.0 \\
73.0 \\
79.0\end{array}$ & $\begin{array}{l}56.6 \\
62.6 \\
68.6 \\
74.6 \\
80.6\end{array}$ & $\begin{array}{l}55.9 \\
61.9 \\
67.9 \\
73.9 \\
79.9\end{array}$ \\
\hline SIL & $\begin{array}{l}34.5 \\
40.5 \\
46.5 \\
52.5 \\
58.5\end{array}$ & $\begin{array}{l}35.8 \\
41.8 \\
47.8 \\
53.8 \\
59.8\end{array}$ & $\begin{array}{l}36.4 \\
42.4 \\
48.4 \\
54.4 \\
60.4\end{array}$ & $\begin{array}{l}37.7 \\
43.7 \\
49.7 \\
55.7 \\
61.7\end{array}$ \\
\hline PNLT & $\begin{array}{l}64.5 \\
71.3 \\
78.0 \\
84.7 \\
91.5\end{array}$ & $\begin{array}{l}69.6 \\
76.5 \\
83.3 \\
90.0 \\
97.0\end{array}$ & $\begin{array}{l}72.9 \\
79.3 \\
85.8 \\
92.3 \\
98.7\end{array}$ & $\begin{array}{l}72.4 \\
79.2 \\
85.9 \\
92.7 \\
99.5\end{array}$ \\
\hline EPNL & $\begin{array}{l}59.1 \\
66.3 \\
73.5 \\
80.6 \\
87.8\end{array}$ & $\begin{array}{l}66.6 \\
73.5 \\
80.5 \\
87.5 \\
94.4\end{array}$ & $\begin{array}{l}66.7 \\
73.4 \\
80.1 \\
86.7 \\
93.4 \\
\end{array}$ & $\begin{array}{l}68.8 \\
75.7 \\
82.5 \\
89.3 \\
96.2\end{array}$ \\
\hline
\end{tabular}


TABLE II.- PRESENTATION ORDER OF LEVEL-SPECTRUM CONDITIONS

BY ACTIVITY FOR EACH SUBJECT PAIR

\begin{tabular}{|c|c|c|c|c|c|c|c|c|c|c|c|}
\hline \multicolumn{2}{|c|}{$\begin{array}{c}\text { Activity } \\
\text { presentation order } \\
\text { (subject pair number) }\end{array}$} & \multicolumn{10}{|c|}{ Stimuli for session - } \\
\hline First & Second & 1 & 2 & 3 & 4 & 5 & 6 & 7 & 8 & 9 & 10 \\
\hline \multicolumn{12}{|c|}{ Activity: Reverie } \\
\hline 1 & 2 & $3 A$ & $3 B$ & $1 \mathrm{~A}$ & $5 A$ & $4 B$ & $7 \mathrm{~B}$ & $4 A$ & $2 A$ & $2 B$ & $5 B$ \\
\hline 3 & 5 & $3 B$ & $5 \mathrm{~A}$ & $3 \mathrm{~A}$ & $1 \mathrm{~B}$ & $1 \mathrm{~A}$ & $2 \mathrm{~A}$ & $4 B$ & $5 B$ & $4 \mathrm{~A}$ & 2B \\
\hline 4 & 7 & $5 \mathrm{~A}$ & $1 \mathrm{~B}$ & $3 B$ & $2 \mathrm{~A}$ & $3 A$ & $5 B$ & $1 \mathrm{~A}$ & $2 B$ & $4 \mathrm{~B}$ & $4 \mathrm{~A}$ \\
\hline 6 & 8 & $1 \mathrm{~B}$ & $2 \mathrm{~A}$ & $5 A$ & $5 B$ & $3 B$ & $2 B$ & $3 \mathrm{~A}$ & $4 A$ & $1 \mathrm{~A}$ & $4 B$ \\
\hline 12 & 9 & $2 \mathrm{~A}$ & $5 B$ & $1 \mathrm{~B}$ & $2 B$ & $5 A$ & $4 \mathrm{~A}$ & $3 B$ & $4 B$ & $3 A$ & $1 \mathrm{~A}$ \\
\hline 13 & 10 & $5 B$ & $2 \mathrm{~B}$ & $2 \mathrm{~A}$ & $4 \mathrm{~A}$ & $1 \mathrm{~B}$ & $4 \mathrm{~B}$ & $5 A$ & $1 \mathrm{~A}$ & $3 B$ & $3 A$ \\
\hline 15 & 11 & $2 B$ & $4 \mathrm{~A}$ & $5 B$ & $4 B$ & $2 A$ & $1 \mathrm{~A}$ & $1 \mathrm{~B}$ & $3 A$ & $5 A$ & $3 B$ \\
\hline 17 & 14 & $4 \mathrm{~A}$ & $4 B$ & $2 B$ & $1 \mathrm{~A}$ & $5 B$ & $3 A$ & $2 A$ & $3 B$ & $1 \mathrm{~B}$ & $5 A$ \\
\hline 18 & 16 & 4B & $1 \mathrm{~A}$ & $4 \mathrm{~A}$ & $3 \mathrm{~A}$ & $2 B$ & $3 B$ & $5 B$ & $5 \mathrm{~A}$ & $2 A$ & $1 \mathrm{~B}$ \\
\hline 19 & 20 & $1 \mathrm{~A}$ & $3 A$ & $4 \mathrm{~B}$ & $3 B$ & $4 \mathrm{~A}$ & $5 A$ & $2 \mathrm{~B}$ & $1 \mathrm{~B}$ & $5 B$ & $2 \mathrm{~A}$ \\
\hline \multicolumn{12}{|c|}{ Activity: Conversation } \\
\hline 2 & 1 & $5 B$ & $2 B$ & $2 \mathrm{~A}$ & $4 \mathrm{~A}$ & $1 \mathrm{~B}$ & $4 B$ & $5 \AA$ & $1 \mathrm{~A}$ & $3 B$ & $3 A$ \\
\hline 5 & 3 & $2 \mathrm{~B}$ & $4 \mathrm{~A}$ & $5 B$ & $4 B$ & $2 A$ & $1 \mathrm{~A}$ & $1 \mathrm{~B}$ & $3 A$ & $5 A$ & $3 B$ \\
\hline 7 & 4 & $4 \mathrm{~A}$ & $4 B$ & $2 B$ & $1 \mathrm{~A}$ & $5 B$ & $3 A$ & $2 \mathrm{~A}$ & $3 \mathrm{~B}$ & $1 \mathrm{~B}$ & $5 A$ \\
\hline 8 & 6 & $4 B$ & $1 \mathrm{~A}$ & $4 \mathrm{~A}$ & $3 \mathrm{~A}$ & $2 B$ & $3 B$ & $5 B$ & $5 A$ & $2 A$ & $1 \mathrm{~B}$ \\
\hline 9 & 12 & $1 \mathrm{~A}$ & $3 A$ & $4 B$ & $3 B$ & $4 A$ & $5 A$ & $2 B$ & $1 \mathrm{~B}$ & $5 B$ & $2 \mathrm{~A}$ \\
\hline 10 & 13 & $3 A$ & $3 B$ & $1 \mathrm{~A}$ & $5 A$ & $4 B$ & $1 \mathrm{~B}$ & $4 \mathrm{~A}$ & $2 A$ & $2 B$ & $5 B$ \\
\hline 11 & 15 & $3 B$ & $5 \mathrm{~A}$ & $3 A$ & $1 \mathrm{~B}$ & $1 \mathrm{~A}$ & $2 \mathrm{~A}$ & $4 \mathrm{~B}$ & $5 B$ & $4 \mathrm{~A}$ & $2 B$ \\
\hline 14 & 17 & $5 \mathrm{~A}$ & $1 \mathrm{~B}$ & $3 B$ & $2 \mathrm{~A}$ & $3 A$ & $5 B$ & $1 \mathrm{~A}$ & $2 \mathrm{~B}$ & $4 B$ & $4 \mathrm{~A}$ \\
\hline 16 & 18 & $1 \mathrm{~B}$ & $2 A$ & $5 \mathrm{~A}$ & $5 B$ & $3 B$ & $2 B$ & $3 \mathrm{~A}$ & $4 \mathrm{~A}$ & $1 \mathrm{~A}$ & 4B \\
\hline 20 & 19 & $2 \mathrm{~A}$ & $5 B$ & $1 \mathrm{~B}$ & $2 B$ & $5 A$ & $4 \mathrm{~A}$ & $3 B$ & $4 B$ & $3 \mathrm{~A}$ & $1 \mathrm{~A}$ \\
\hline
\end{tabular}

\begin{tabular}{|c|c|}
\hline \multicolumn{2}{|c|}{ stimuli key } \\
\hline $\begin{array}{c}\text { Average noise } \\
\text { level, } L_{A}, \\
d B\end{array}$ & Spectrum \\
\hline $\begin{array}{l}7=73.1 \\
2=55.1 \\
3=61.1 \\
4=79.1 \\
5=67.1\end{array}$ & $\begin{array}{l}A=\text { Low frequency } \\
B=\text { High frequency }\end{array}$ \\
\hline
\end{tabular}


TABLE III.- SUMMARY OF ANALYSIS OF VARIANCE: ANNOYANCE OF NOISE

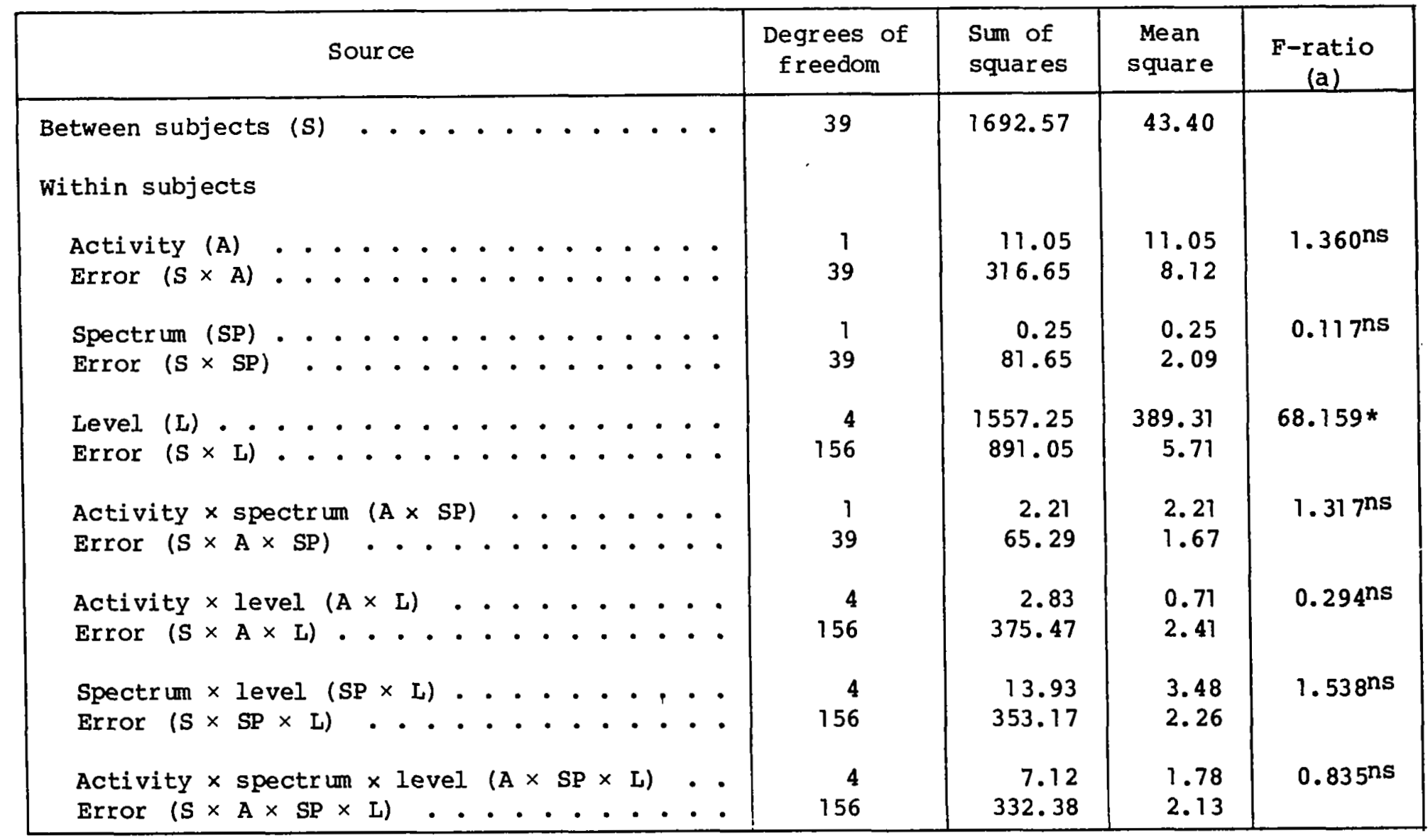

a Superscript ns indicates not significant, and * indicates significant at 0.01 level. 
TABLE IV.- CORRELATION MATRIX AND t-TEST VALUES FOR SIGNIFICANT DIFFERENCES BETWEEN CORRELATION COEFFICIENTS OF ANNOYANCE AND NOISE METRICS

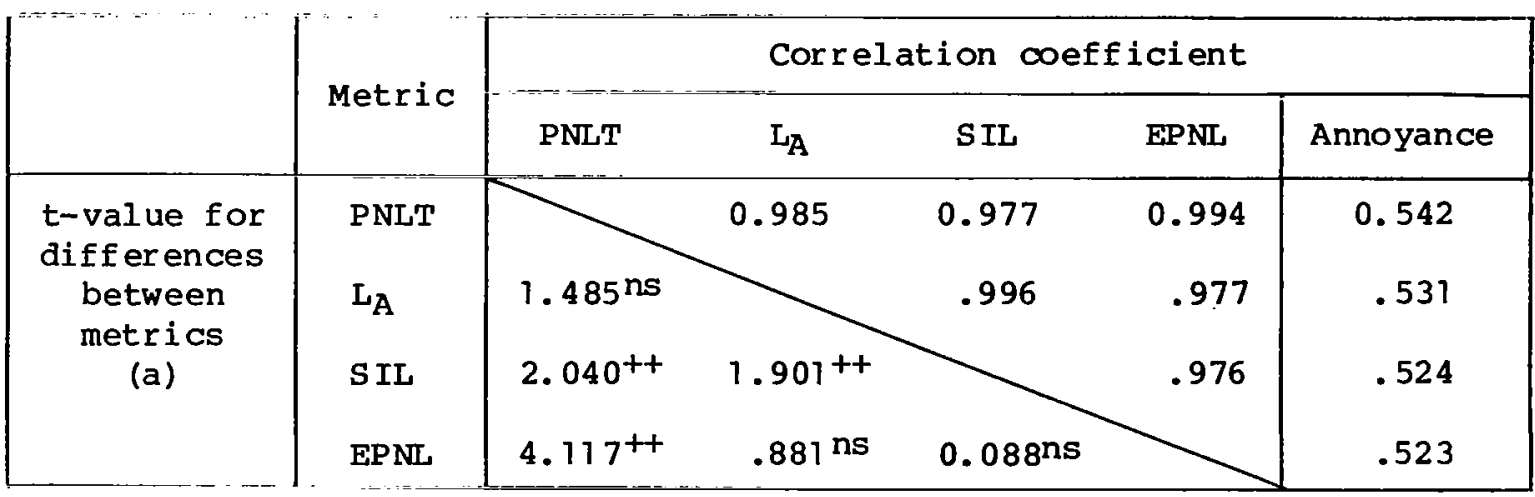

asuperscript ns indicates not significant; and ++ indicates signifi$\left(r_{12}-r_{13}\right) \sqrt{(n-3)\left(1+r_{23}\right)}$

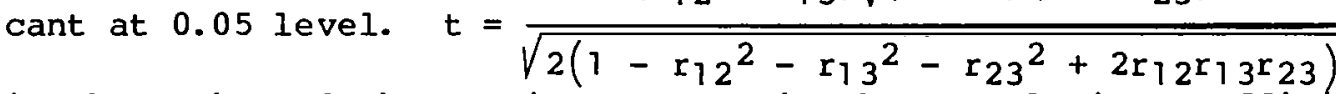
is the number of observations, $r 12$ is the correlation coefficient between one noise metric and annoyance, and $r_{13}$ is the correlation coefficient between a second noise metric and annoyance, and $r_{23}$ is the intercorrelation between the two noise metrics. 
TABLE V.- SUMMARY OF ANALYS IS OF VARIANCE: DIFFICULTY OF CONVERSATION IN NOISE

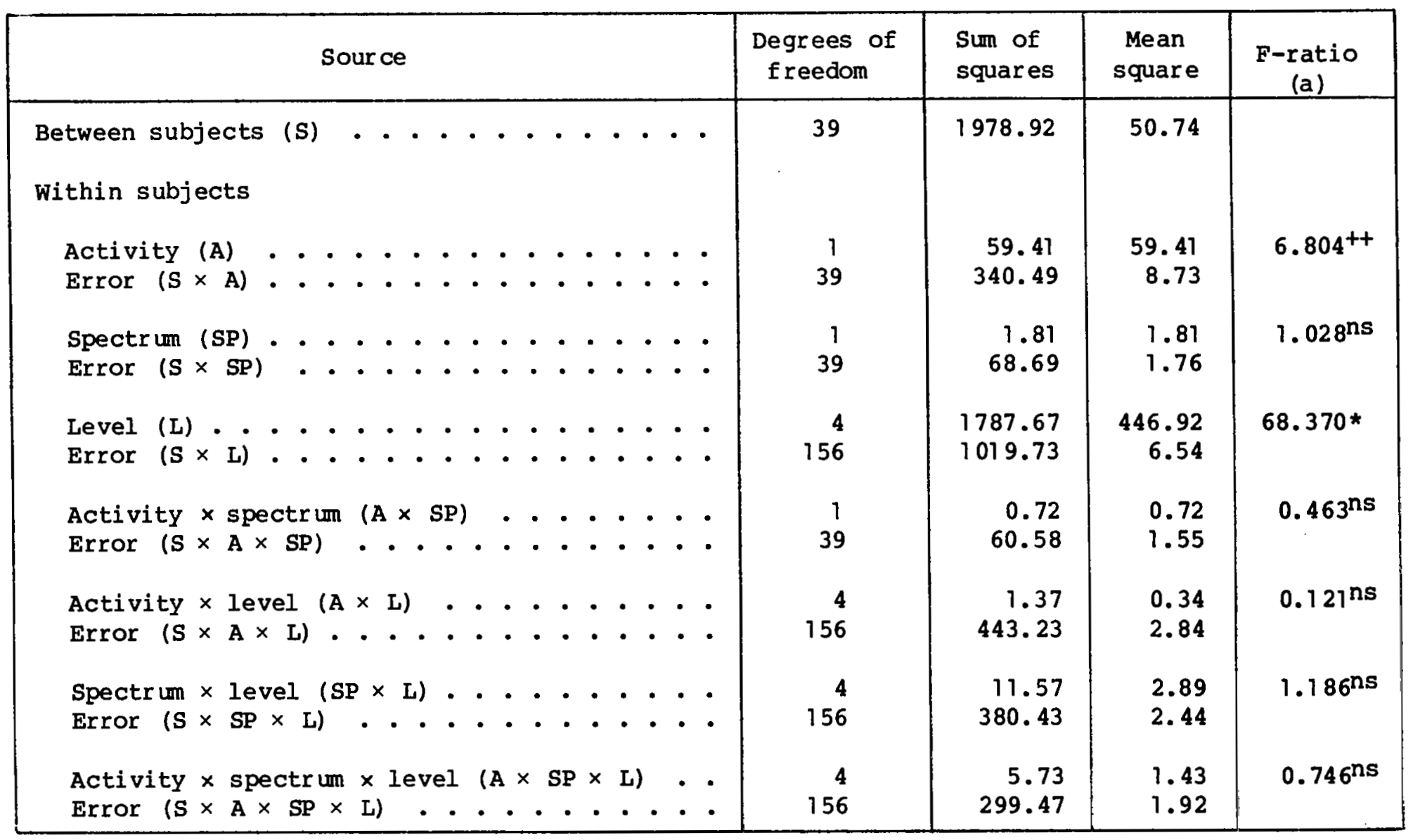

a Superscript ns indicates not significant; * indicates significant at 0.01 level; and ++ indicates significant at 0.05 level. 
TABLE VI.- SUMMARY OF ANALYSIS OF VARIANCE: ACCEPTABILITY OF NOISE FOR CONVERSATION

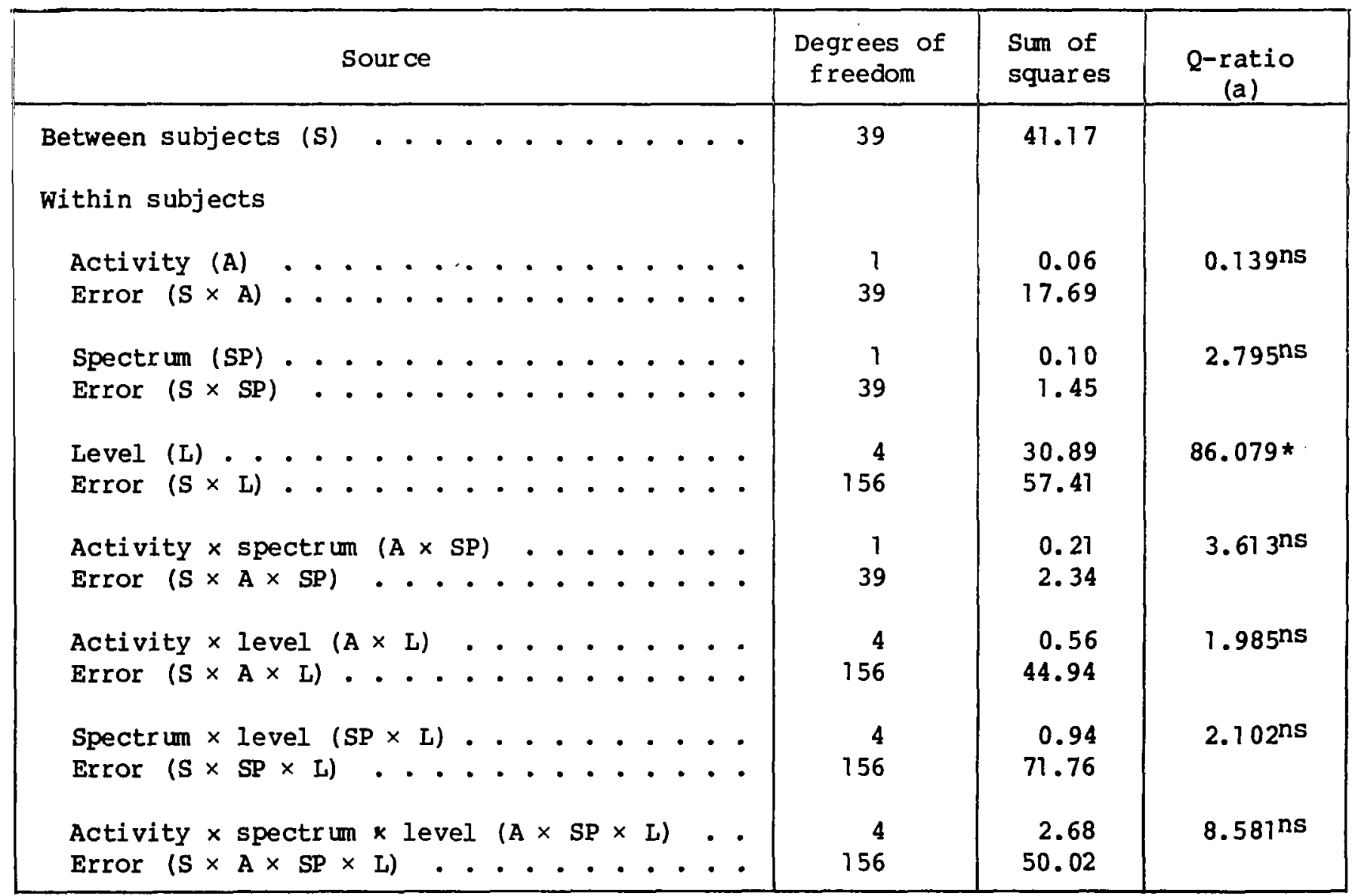

a Superscript ns indicates not significant; * indicates significant at 0.01 level; and $n(k-1) S_{\text {source }}$

$Q=\frac{\text { SS }_{\text {error }}}{\text { Q }}$ 
TABLE VII.- SUMMARY OF ANALYSIS OF VARIANCE: INCREASED VOCAL EFFORT DURING FLYOVER

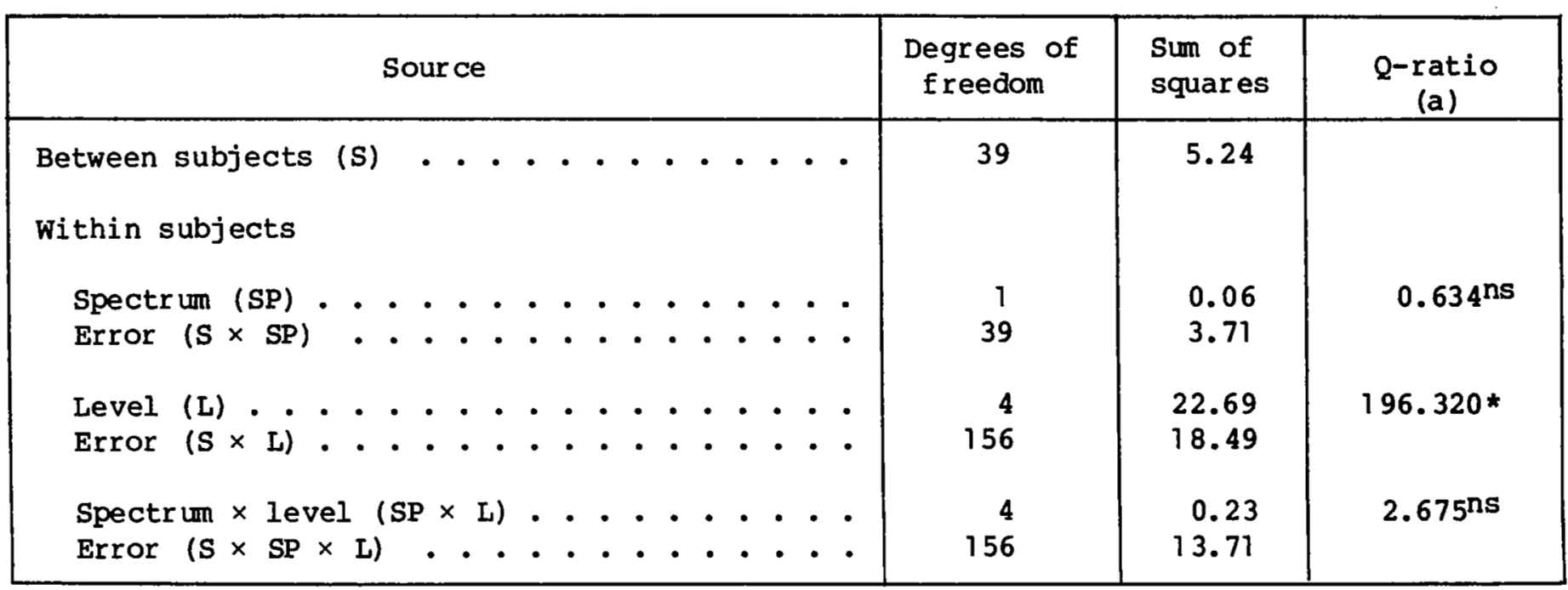

asuperscript ns indicates not significant; * indicates significant at 0.01 level; and $n(k-1)$ SS $_{\text {source }}$

$Q=\frac{n(k-1) S_{\text {source }}}{\text { SS }_{\text {error }}}$ 
TABLE VIII.- SUMMARY OF ANALYSIS OF VARIANCE: INTERRUPTION OF CONVERSATION BASED ON NUMBER OF TIMES SUBJECTS STOPPED TALKING DURING FLYOVERS

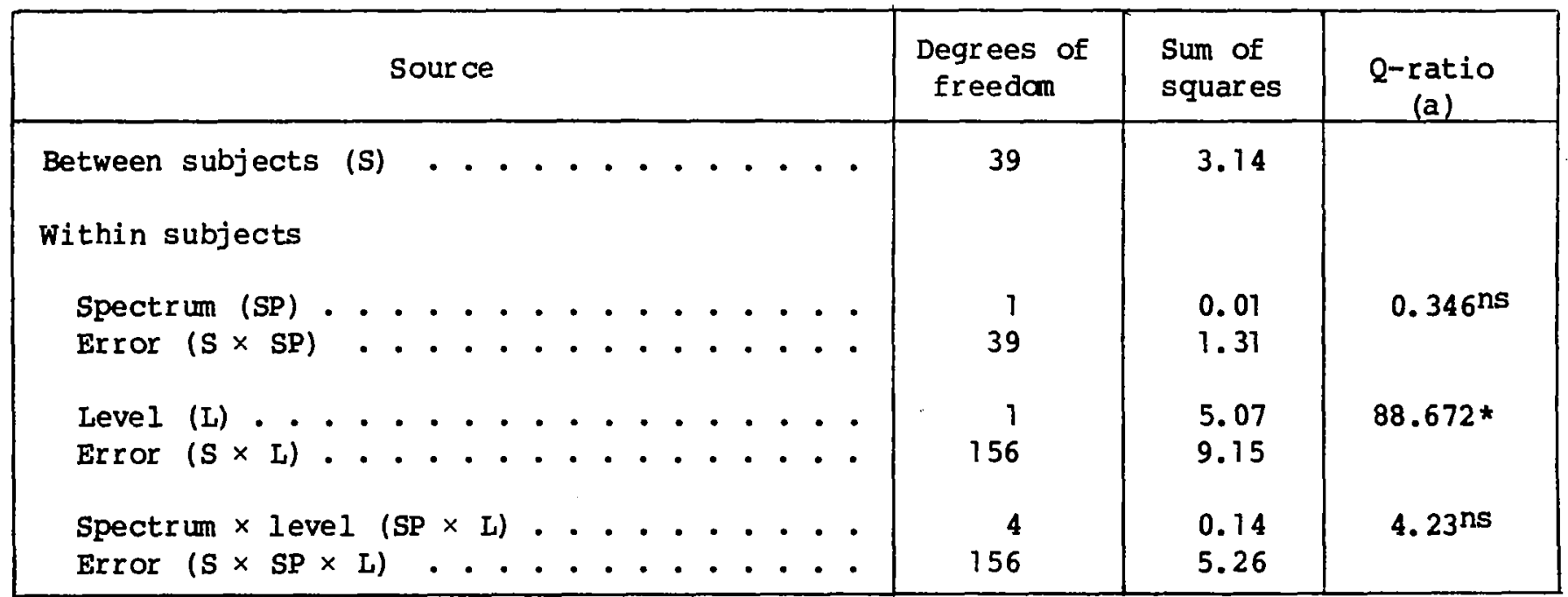

asuperscript ns indicates not significant; * indicates significant at 0.01 level; and $Q=\frac{n(k-1) s s_{\text {source }}}{\text { ss }}$ error 
TABLE IX.- MULTIPLE REGRESSION OF ANNOYANCE ON INCREASED VOCAL EFFORT COVARIED BY PNLT

\begin{tabular}{|l|c|c|c|c|}
\hline Variable entered & $\begin{array}{c}\text { F to enter } \\
\text { regression } \\
\text { equation }\end{array}$ & $\mathrm{R}$ & $\mathrm{R}^{2}$ & \multicolumn{1}{c|}{$\begin{array}{c}\text { Change } \\
\text { in } \mathrm{R}^{2}\end{array}$} \\
\hline PNLT & 53.72676 & 0.54207 & 0.29384 & 0.29384 \\
Increased 1 & 2.40554 & .54233 & .29472 & .00028 \\
Increased 3 & .15588 & .54233 & .29412 & .00000 \\
Increased 2 & .01560 & .54297 & .29482 & .00070 \\
Increased 1 $\times$ PNLT & 2.62623 & .54740 & .29965 & .00483 \\
Increased 2 & .04818 & .54750 & .29975 & .00010 \\
Increased 3 $\times$ PNLT & .12847 & .54771 & .29998 & .00023 \\
\hline
\end{tabular}

ancreased 1, Increased 2, and Increased 3 indicate variables: increased vocal effort during flyover peaks, one, two, or three times, respectively, per session. 
TABLE X.- MULTIPLE REgRESS ION OF ANNOYANCE ON CONVERSATION

INTERRUPTION COVARIED BY PNLT

\begin{tabular}{|c|c|c|c|c|}
\hline $\begin{array}{c}\text { Variable entered } \\
\text { (a) }\end{array}$ & $\begin{array}{l}\text { F to enter } \\
\text { regression } \\
\text { equation }\end{array}$ & $\mathbf{R}$ & $\mathrm{R}^{2}$ & $\begin{array}{l}\text { Change } \\
\text { in } R^{2}\end{array}$ \\
\hline PNLT & 113.10785 & 0.54207 & 0.29384 & 0.29384 \\
\hline Stopped 3 & .24505 & .54507 & .29710 & .00326 \\
\hline Stopped 2 & .62049 & .54579 & .29789 & .00079 \\
\hline Stopped 1 & 1.98061 & .54589 & .29800 & .00011 \\
\hline Stopped $1 \times$ PNLT & 1.94632 & .54893 & .30132 & .00332 \\
\hline Stopped $3 \times$ PNLT & .33309 & .54946 & .30190 & .00058 \\
\hline Stopped $2 \times$ PNLT & .68058 & .55056 & .30311 & .00121 \\
\hline
\end{tabular}

astopped 1, Stopped 2, and stopped 3 indicate variables: stopped talking during flyover peaks, one, two, or three times, respectively, per session. 


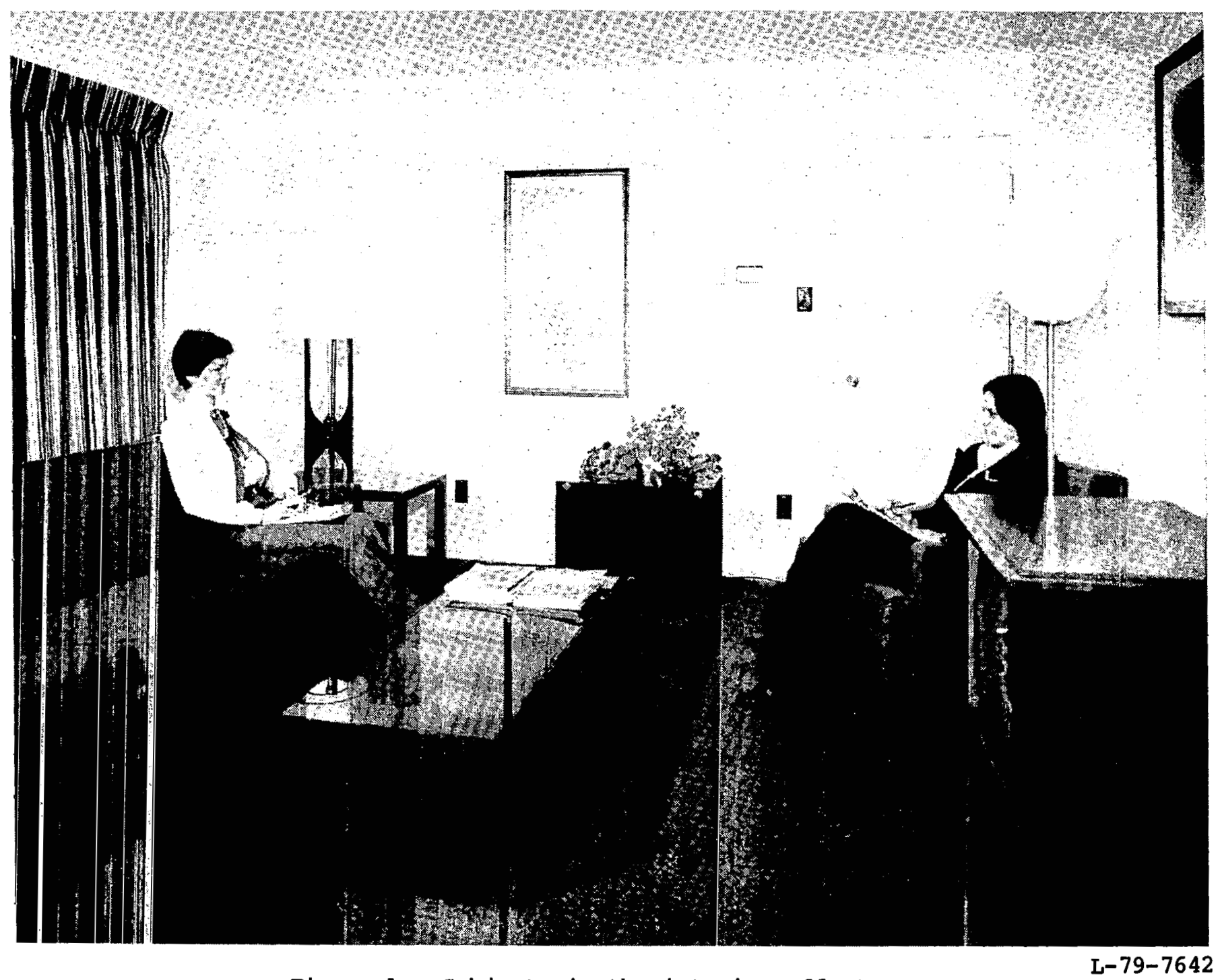

Figure 1.- Subjects in the interior effects room. 


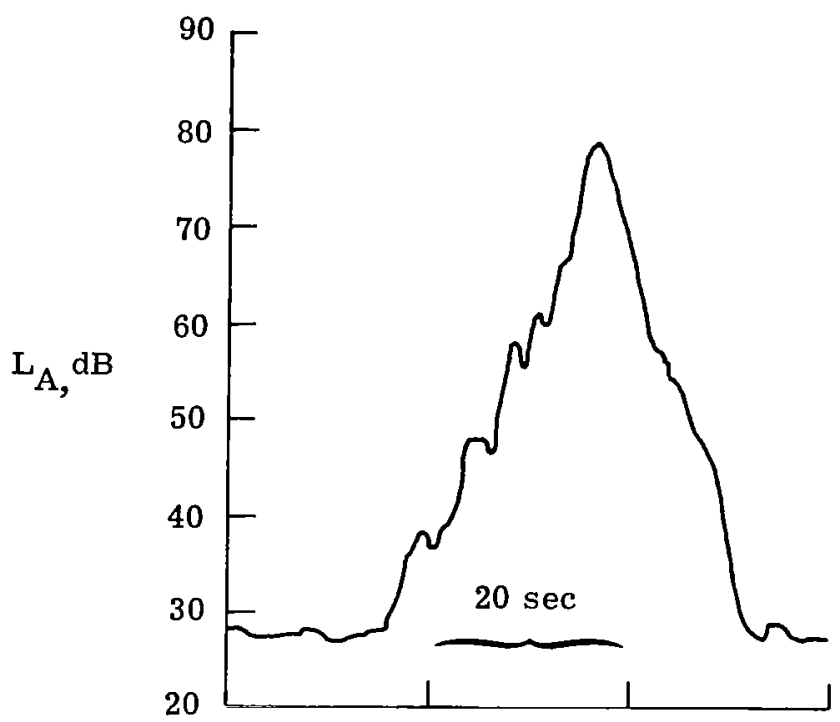

Time, sec

(a) Time history.

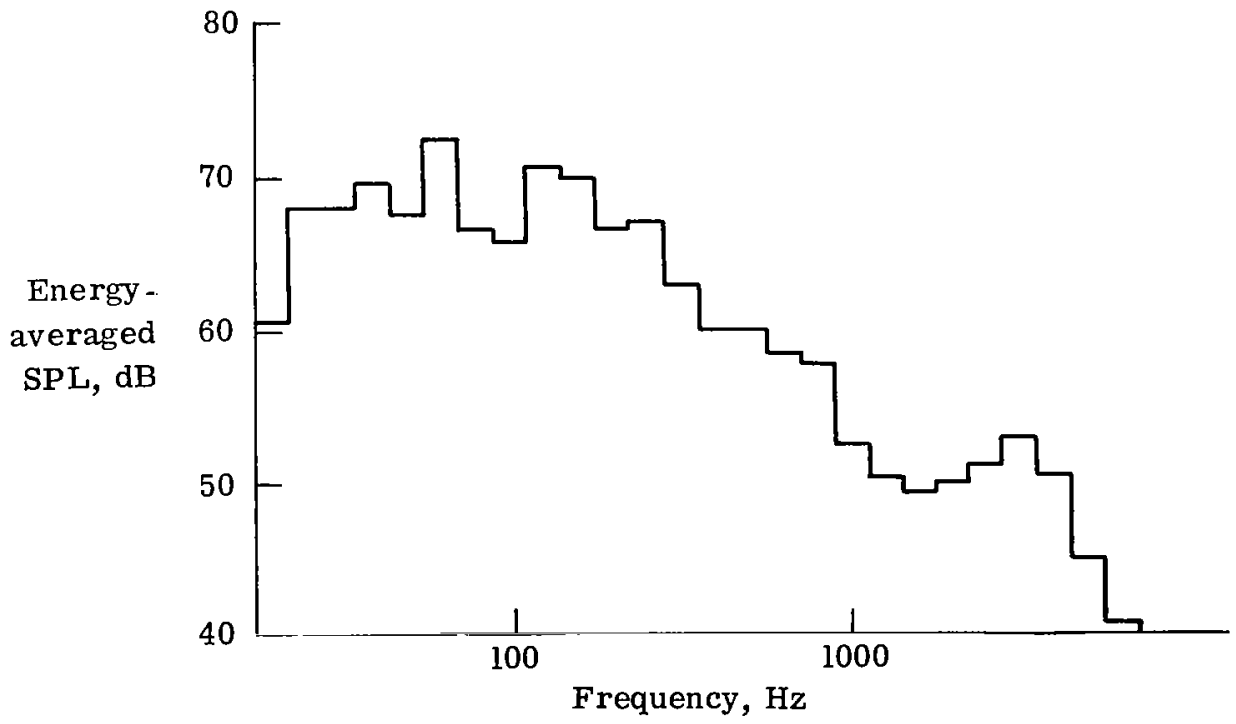

(b) One-third octave band center frequency spectrum.

Figure 2.- Noise characteristics of Concorde landing, $1.6 \mathrm{~km}$ from touchdown, as measured in the left subject seat of the interior effects room. 


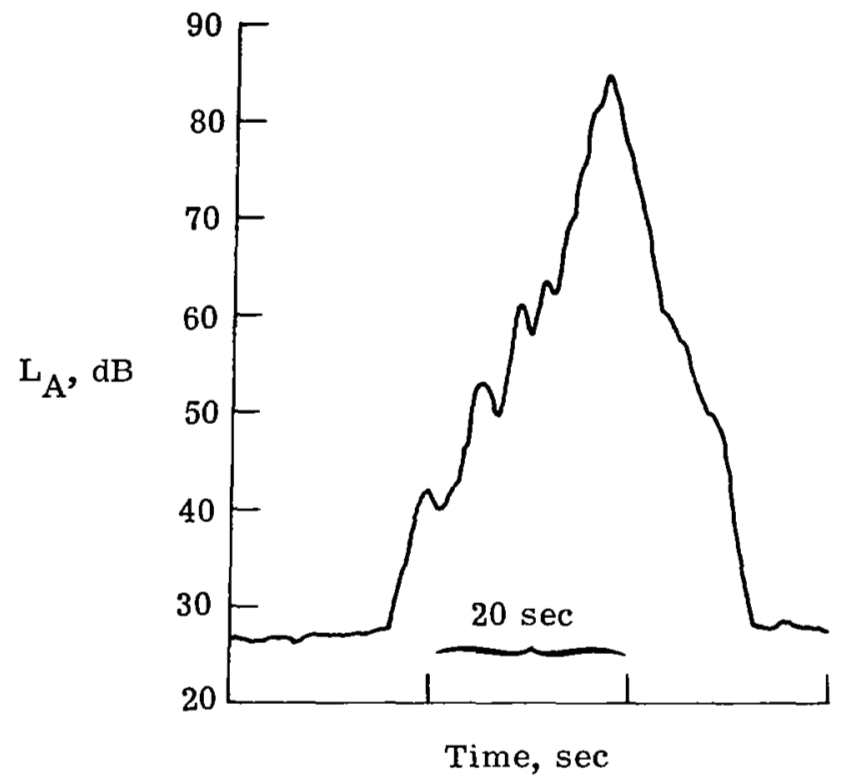

(a) Time history.

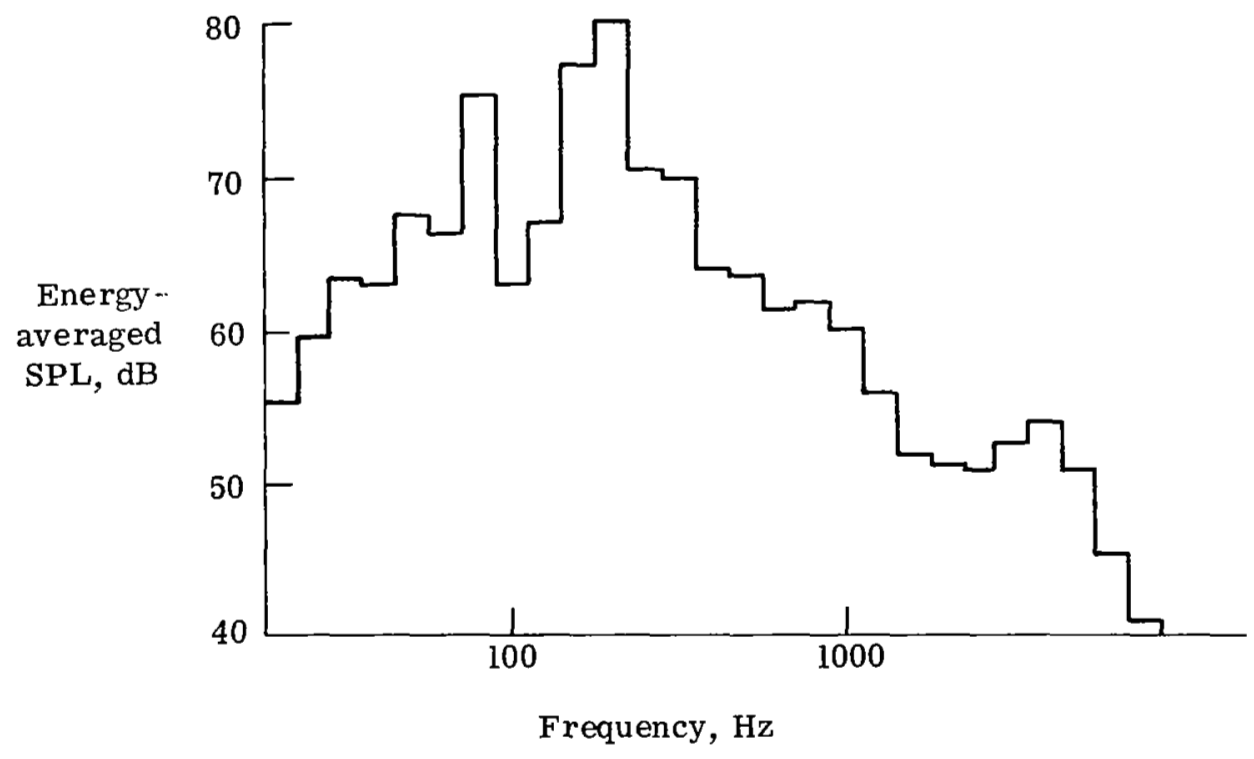

(b) One-third octave band center frequency spectrum.

Figure 3.- Noise characteristics of Concorde landing, $1.6 \mathrm{~km}$ from touchdown, as measured in the right subject seat of the interior effects room. 


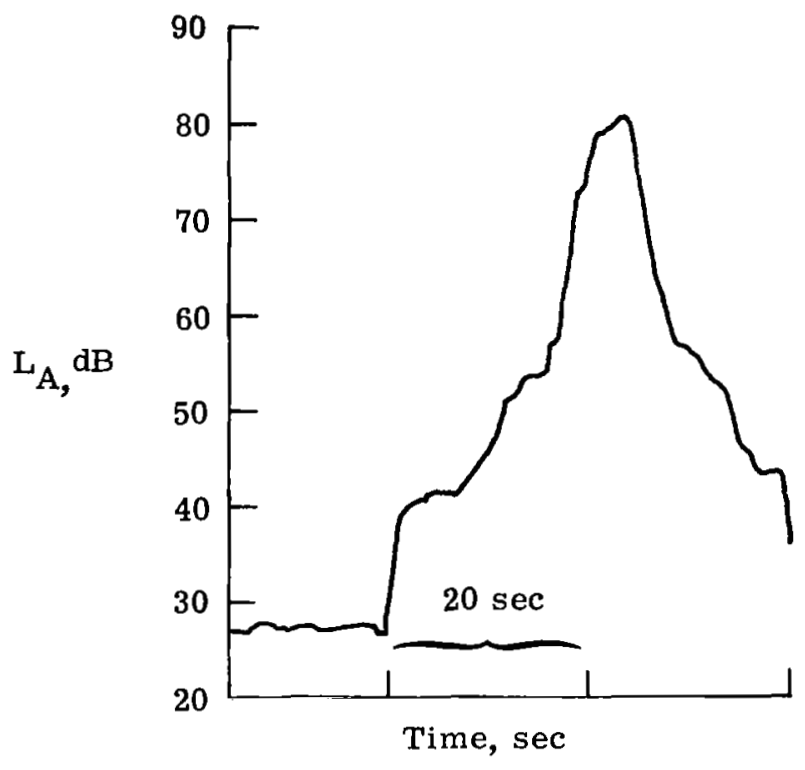

(a) Time history.

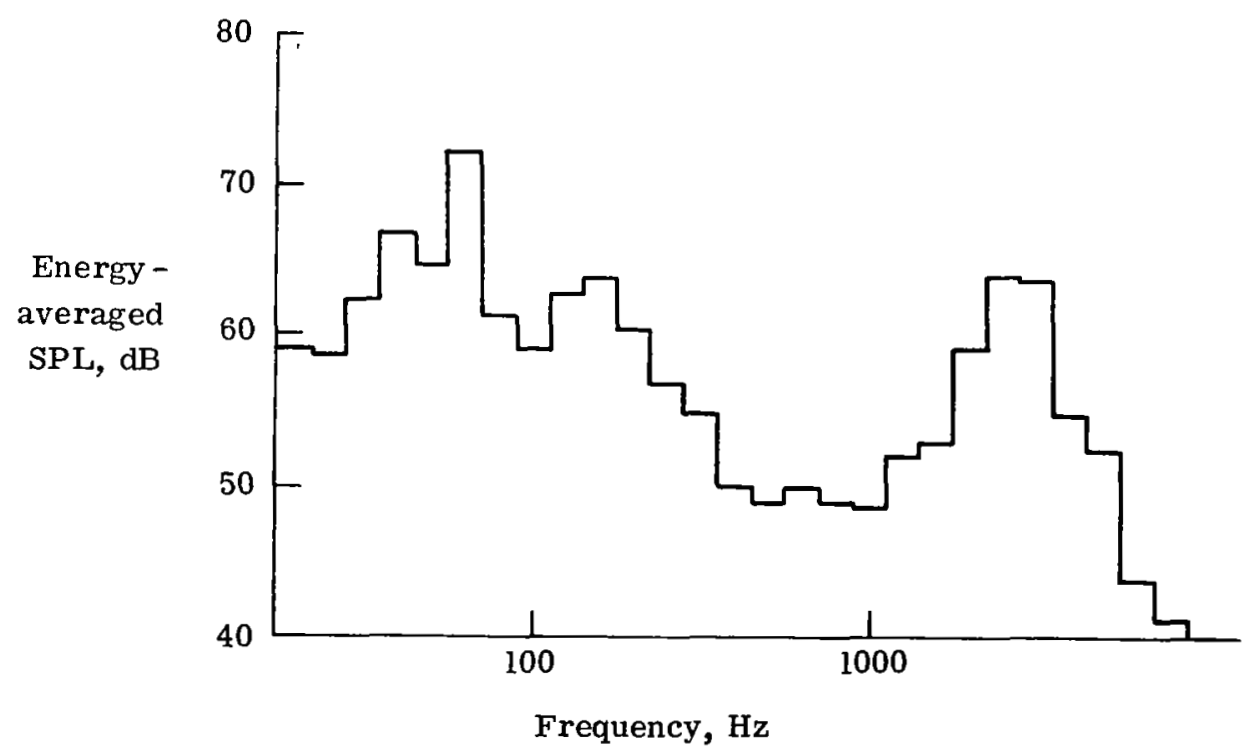

(b) One-third octave band center frequency spectrum.

Figure 4.- Noise characteristics of Boeing 707 landing, $1.6 \mathrm{~km}$ from touchdown, as measured in the left subject seat of the interior effects room. 


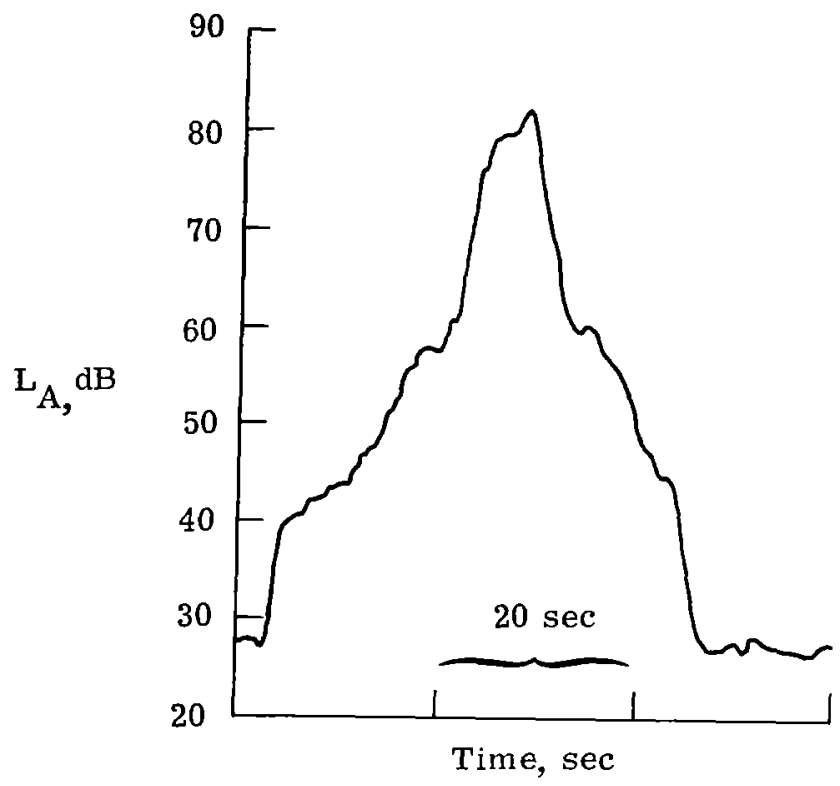

(a) Time history.

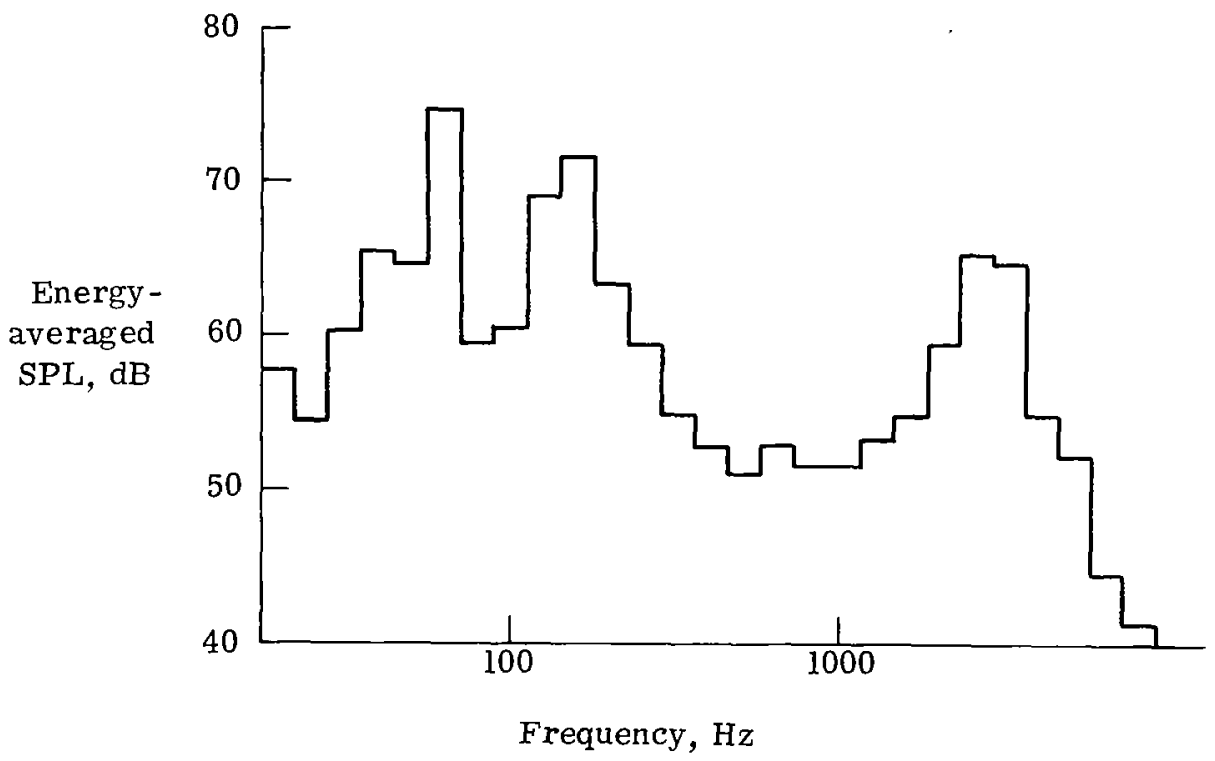

(b) One-third $\propto$ tave band center frequency spectrum.

Figure 5.- Noise characteristics of Boeing 707 landing, $1.6 \mathrm{~km}$ from touchdown, as measured in the right subject seat of the interior effects room. 


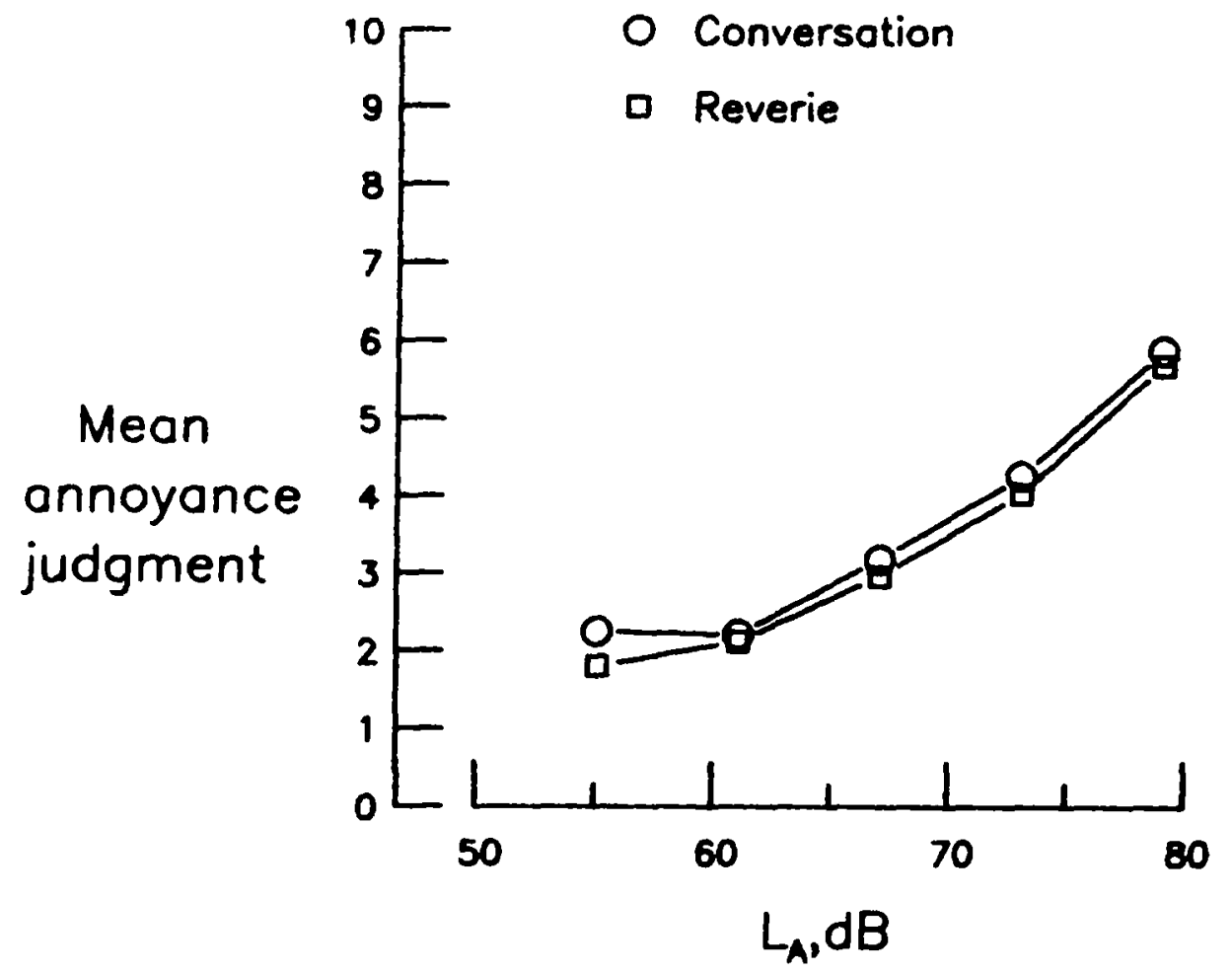

Figure 6.- Effects of noise level $I_{A}$ on annoyance, indicating trend of activity difference. 


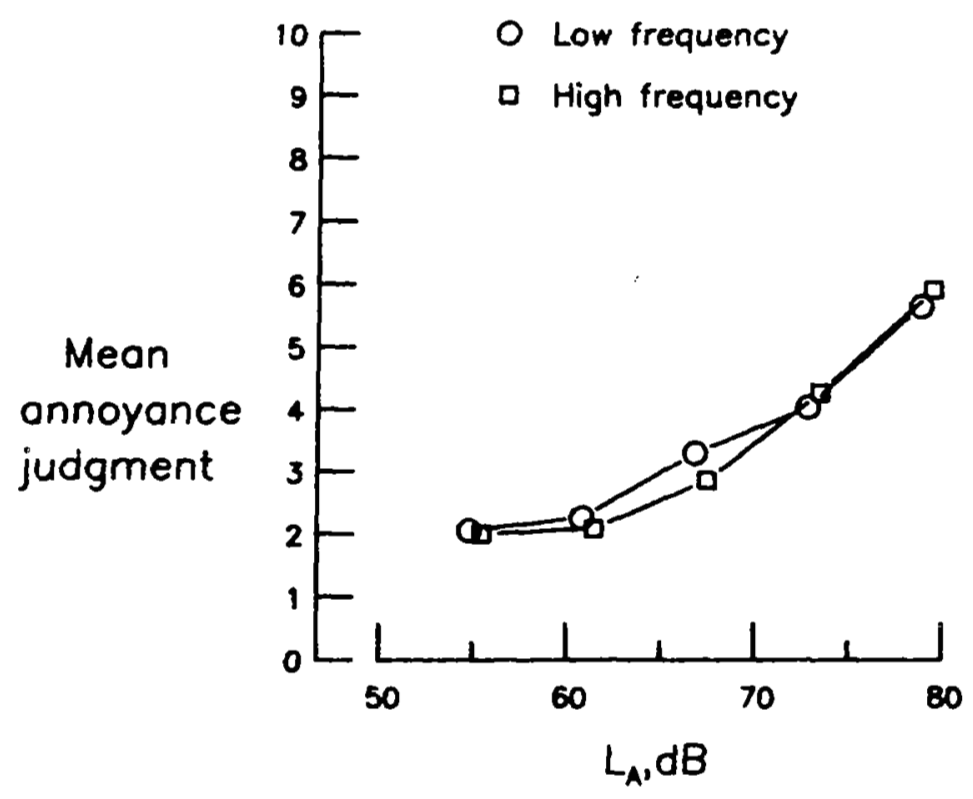

(a) Noise metric, $L_{A}$.

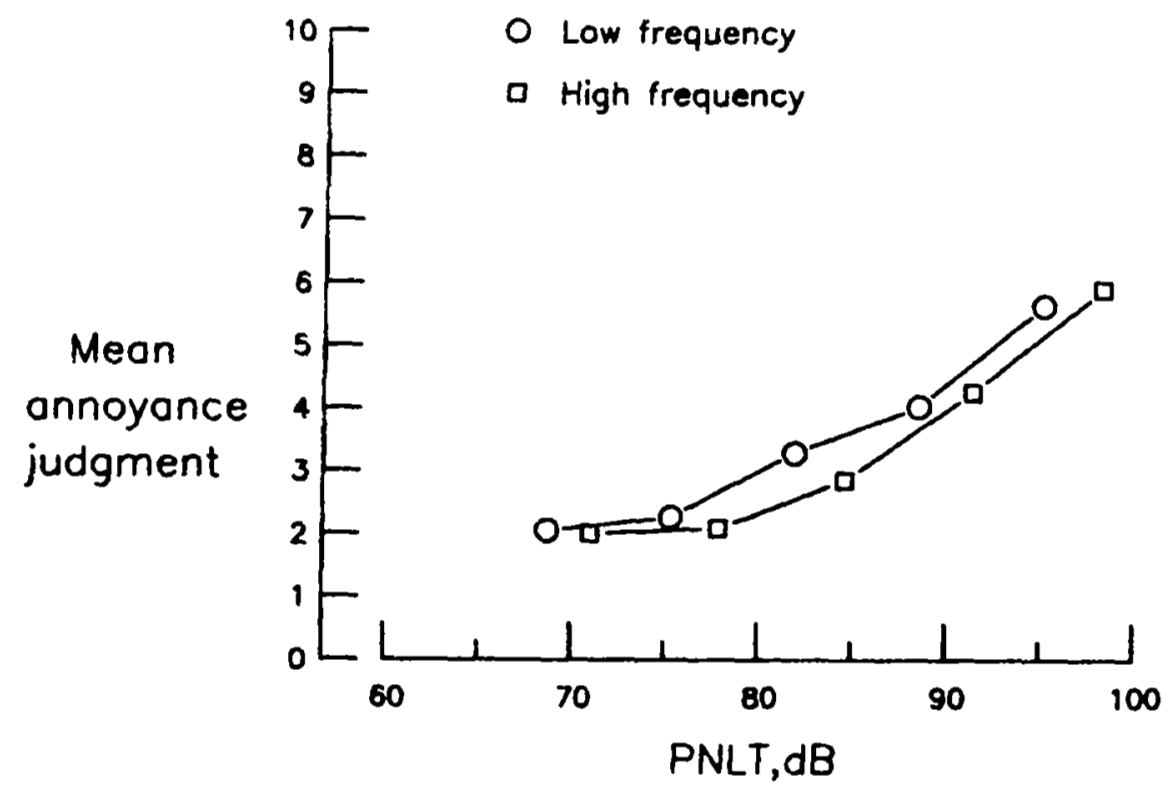

(b) Noise metric, PNLT.

Figure 7.- Effects of noise level on annoyance, indicating trend of spectrum difference. 


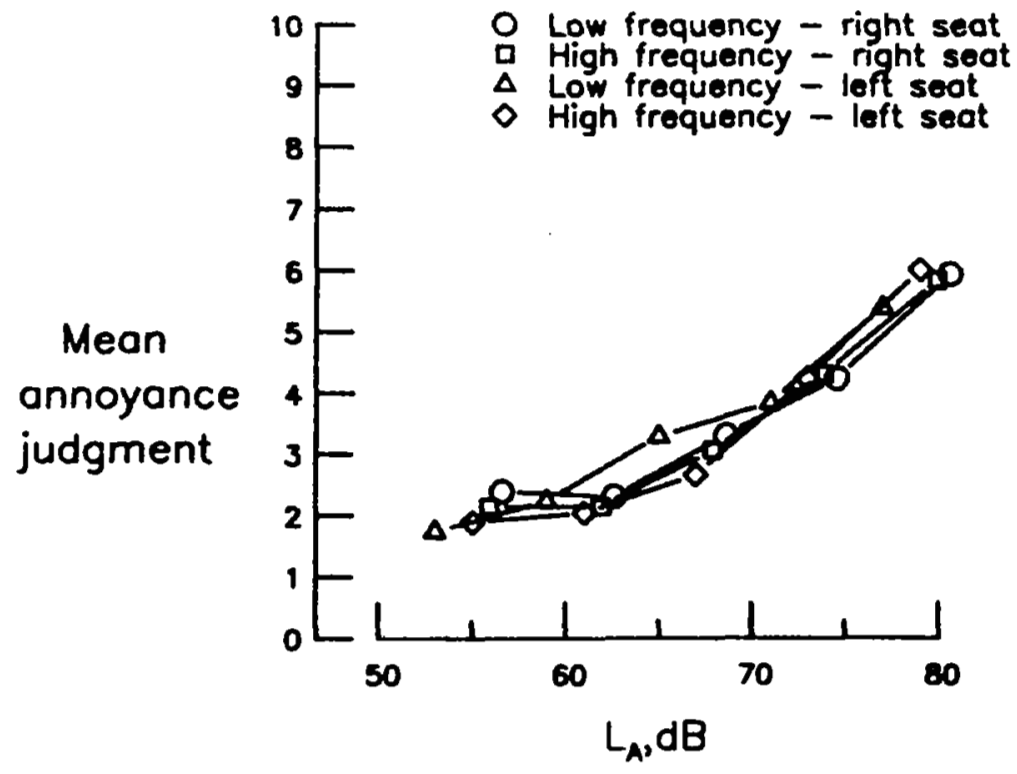

(a) Noise metric, $L_{A}$.

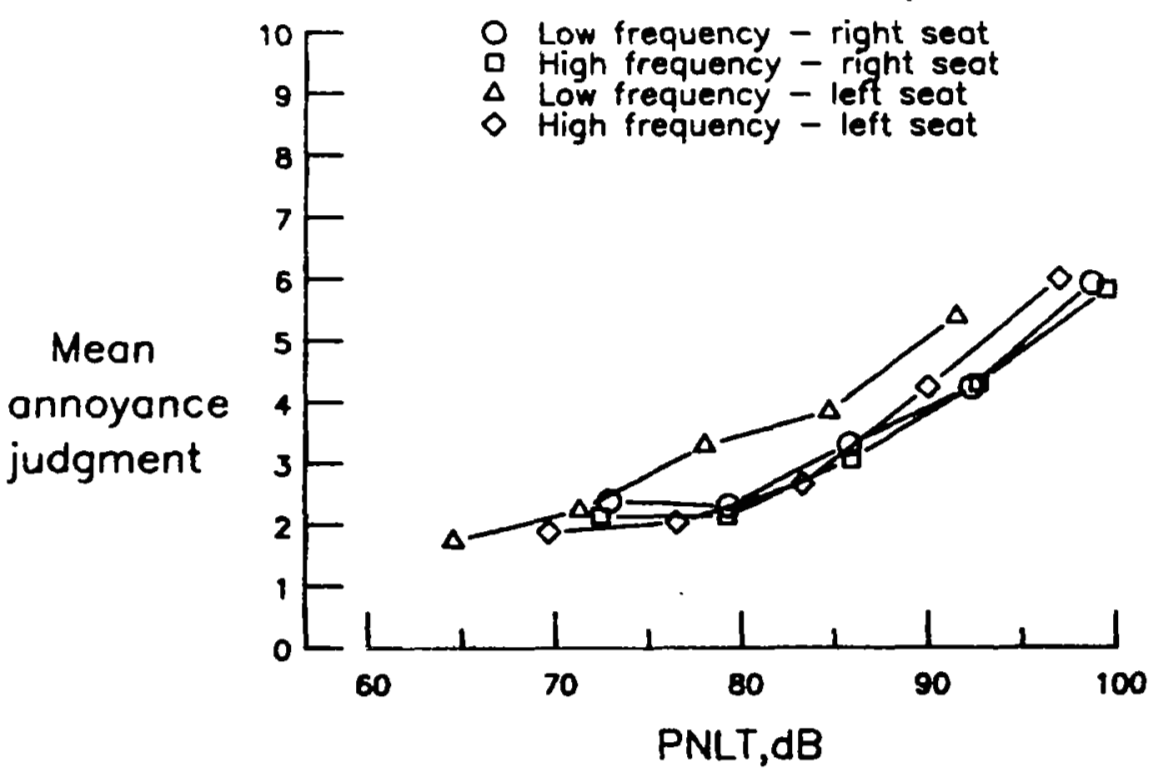

(b) Noise metric, PNLT.

Figure 8.- Effects of noise level of each seat position on annoyance. 


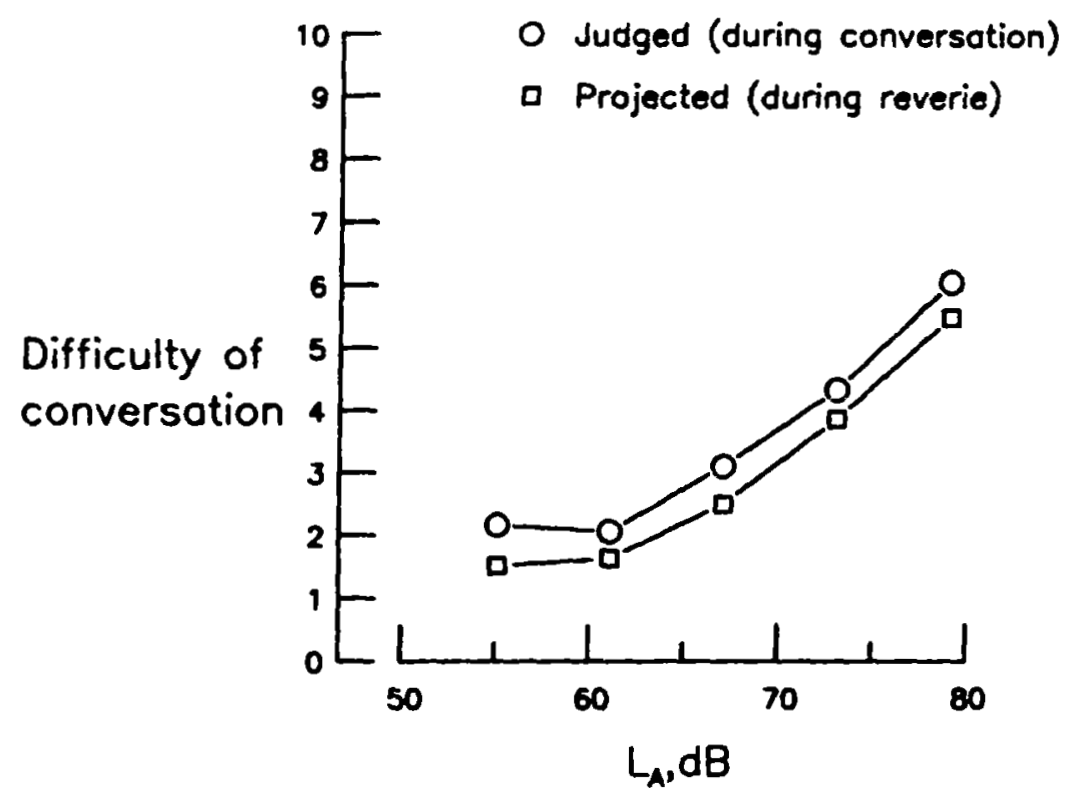

Figure 9.- Effects of noise level, $L_{A}$, on judged and projected difficulty of conversation.

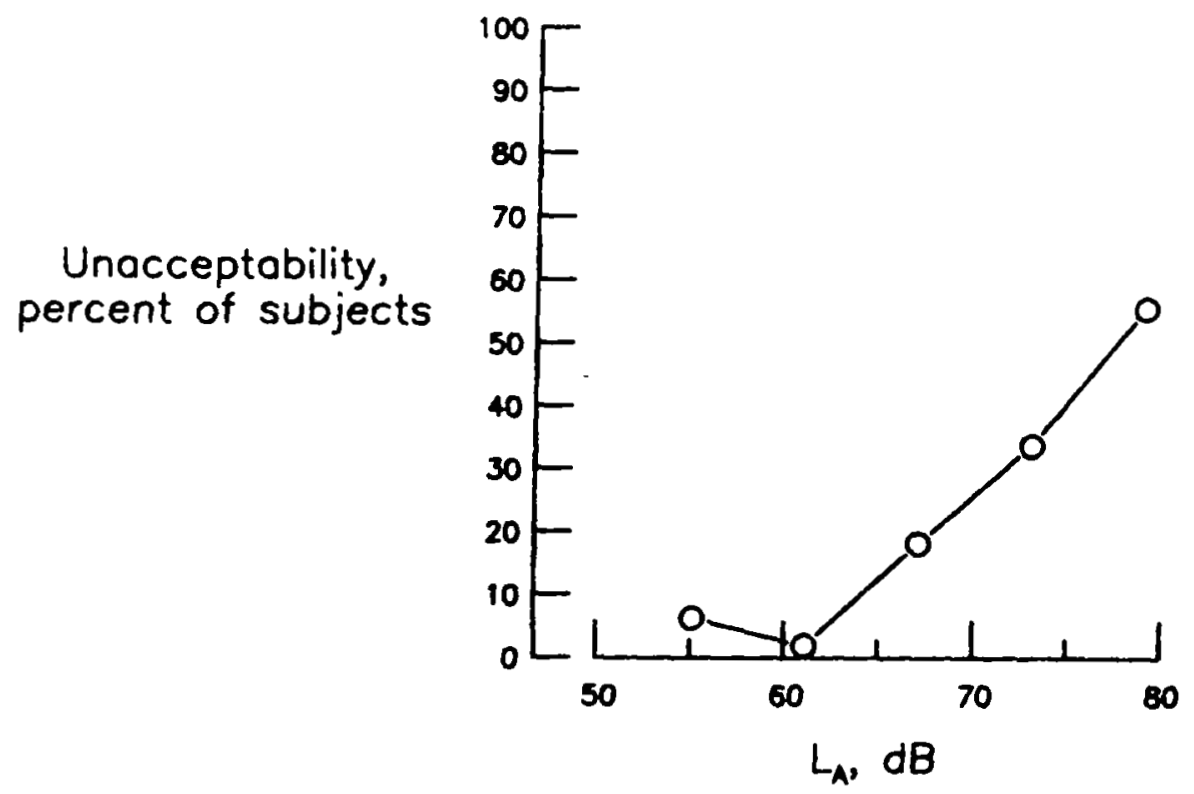

Figure 10.- Effect of noise level on unacceptability of noise for conversation. 


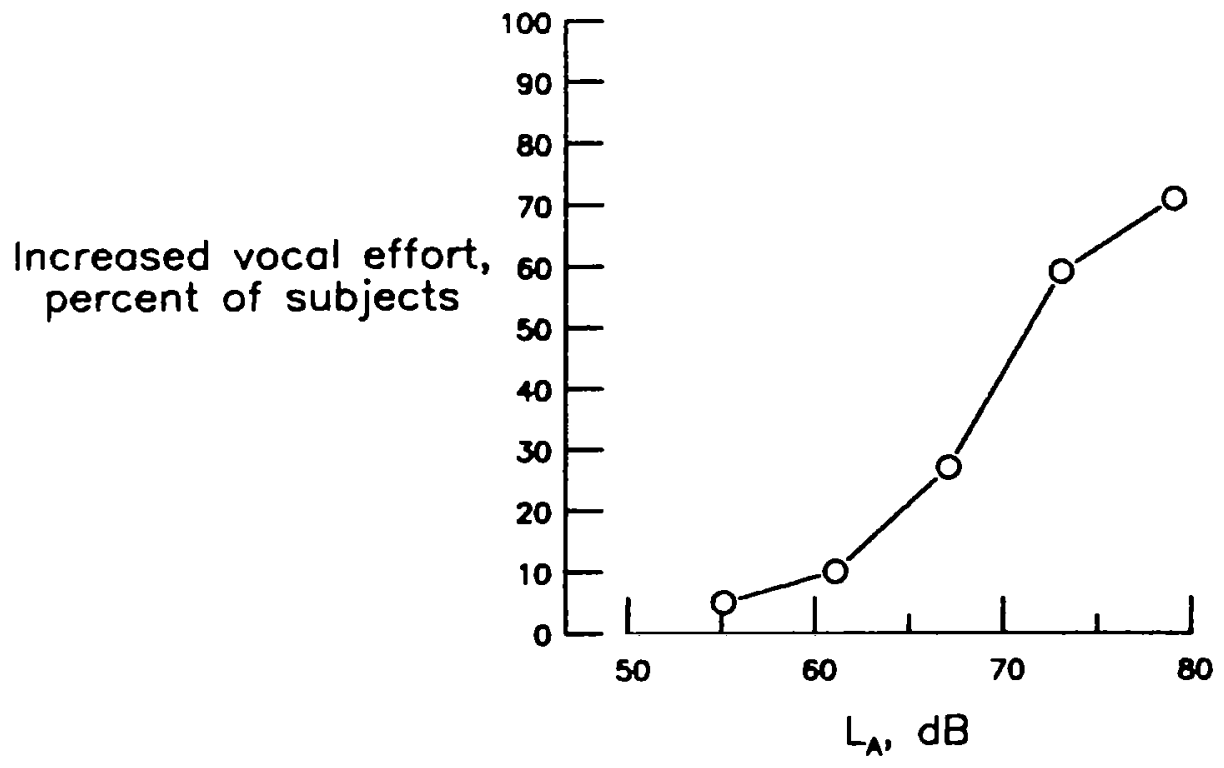

Figure 11.- Effect of noise level on vocal effort.

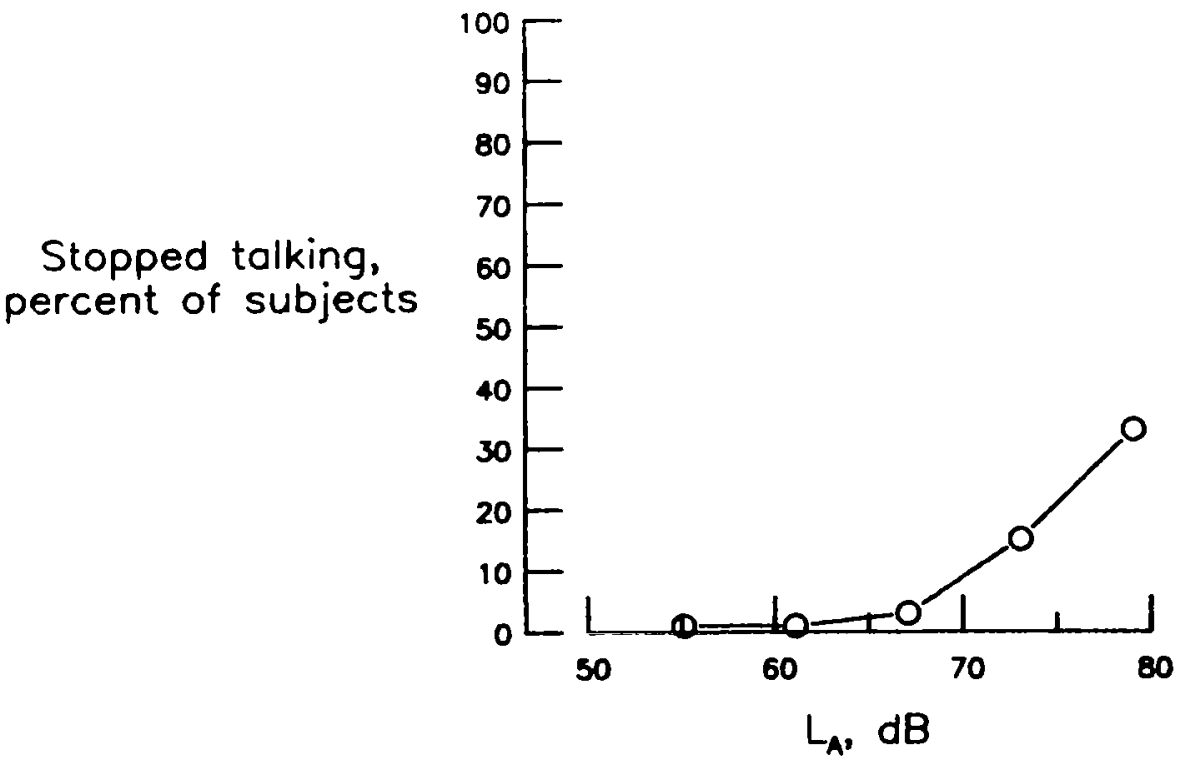

Figure 12.- Effect of noise level on conversation interruption. 


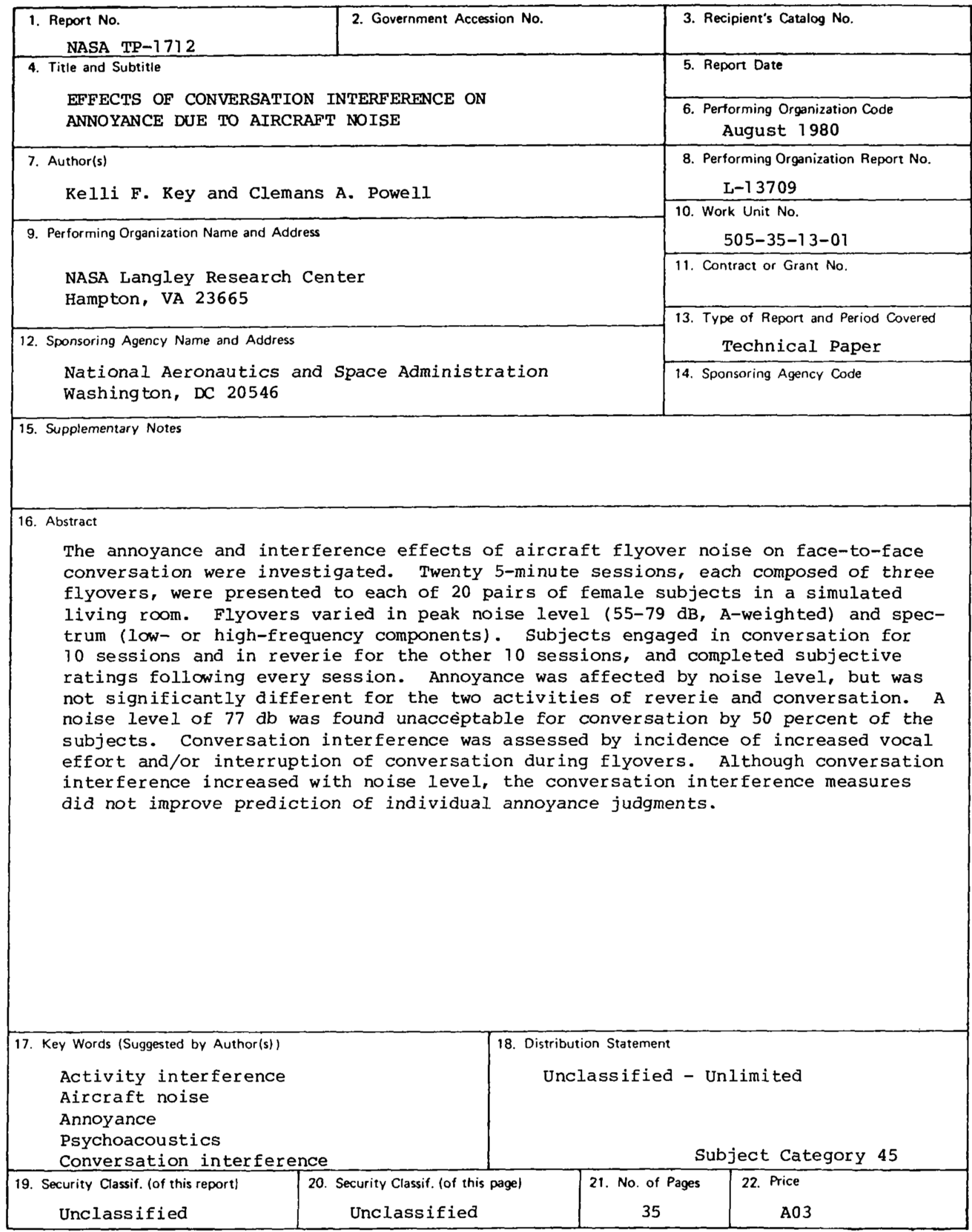

For sale by the National Technical Information Service. Springfield. Virgınia 22161 
